\title{
THE VALUES OF $\triangle$ fHo298.15 AND So298.15 OF THE RADICALS, FORMED BY THE ABSTRACTION OF H ATOM FROM THE p-BENZYLPHENOL AND DIMETHYL PHTHALATE
}

\author{
Gregory Poskrebyshev ${ }^{1}$ \\ ${ }^{1}$ N.N. Semenov Federal Research Center for Chemical Physics, Russian Academy of \\ Sciences, Moscow, Russian Federation
}

April 23, 2021

\begin{abstract}
In the present work, the standard thermochemical properties of the most thermochemically stable radicals (p-Benzylenephenol and 1-Methyl-2-methylene phthalate), formed by abstraction of the hydrogen atom from the p-Benzylphenol and Dimethyl phthalate are determined using the results of B3LYP/6-311++G(d,p), M06-2X/6-311++G(d,p) and RO/CBS-4M calculations. The consistent values of the standard enthalpies of formation of these structures are determined using the corrected thermochemistry of the homodesmotic and atomization reactions. The values of the standard entropies of these compounds and the temperature dependencies of their thermochemical properties are also calculated in the present work. It is found that the H-transfer reaction of HO2 with p-Benzylenephenol is thermochemically favorable and can lead to the chain oxidation of p-Benzylenephenol at relatively low temperatures.
\end{abstract}

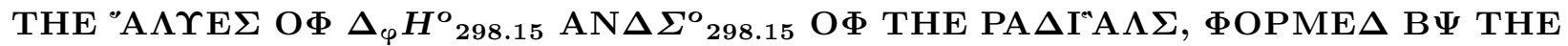

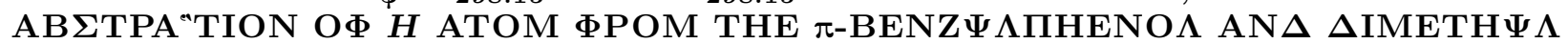
ПНТНА А АТЕ

Gregory A. Poskrebyshev

V.L. Tal'rose Institute of Energy Problems for Chemical Physics at Federal Research Center for Chemical Physics, Russian Academy of Sciences, 119334, Moscow, Russia, Leninsky prosp., bldg. 38-2

poskr@yahoo.com

Abstract. In the present work, the standard thermochemical properties of the most thermochemically stable radicals (p-Benzylenephenol and 1-Methyl-2-methylene phthalate), formed by abstraction of the hydrogen atom from the p-Benzylphenol and Dimethyl phthalate are determined using the results of B3LYP/6$311++\mathrm{G}(\mathrm{d}, \mathrm{p}), \mathrm{M} 06-2 \mathrm{X} / 6-311++\mathrm{G}(\mathrm{d}, \mathrm{p})$ and RO/CBS-4M calculations. The consistent values of the standard enthalpies of formation of these structures are determined using the corrected thermochemistry of the homodesmotic and atomization reactions.

The values of the standard entropies of these compounds and the temperature dependencies of their thermochemical properties are also calculated in the present work.

It is found that the $\mathrm{H}$-transfer reaction of $\mathrm{HO}_{2}$ with p-Benzylenephenol is thermochemically favorable and can lead to the chain oxidation of p-Benzylenephenol at relatively low temperatures. 
Keywords: p-Benzylenephenol, 1-Methyl-2-methylene phthalate, Enthalpy, Entropy

\section{INTRODUCTION}

The bio-oil is the intermediate product, formed during the conversion of biomass to the end products such as chemicals or fuels. Development of the technology of conversion of the bio-oil to the end products requires the definition of the target compounds as well as the optimization of conditions for their production. At the present moment, the main products of non biochemical conversion of bio-oil are the synthesis gas and diesel fuel. However, the production of other chemical compounds from such chemical rich composition is not excluded.

The computer modeling of the chemical processes using the detailed physico-chemical mechanism is one of the possible approaches for the determination of the possible products, as well as for the optimization of the conditions for the conversion of the bio-oil. This modeling cannot be done without simplification of the composition of bio-oil, contained several hundreds different chemicals [1]. The main problem for that is the deficit of the reaction kinetics and thermochemical data, related to the mechanism and the energy of decomposition and oxidation of these compounds. As a result, the simplified composition (surrogate), for which this information is seems feasible, must be used instead [2-7].

Ones of the main components of such surrogate mixture, considered previously [8-10], are the phenol and benzene derivatives (2,4-dimethylphenol (2,4-xylenol), 2-methoxy-4-methylphenol, 3-methoxy-4-formylphenol (vanillin), p-Benzylphenol, Dimethyl phthalate), produced during the fast pyrolysis of the wood based biomass [1] capable to imitate the main physico-chemical properties of the products of pyrolytic decomposition of lignin. The structure and thermochemical properties of the first three of these components, as well as of the radicals, formed by abstraction of $\mathrm{H}$ atom from them, are measured [11-13] and calculated using the modern quantum mechanical approaches [13-15]. Thus, the structure and thermochemical properties of the radicals formed by the abstraction of $\mathrm{H}$ atom from the first three compounds are studied previously [16, 17]. The thermochemical properties of last two components (p-Benzylphenol and Dimethyl phthalate) are also measured [18-20] and calculated [21]. However, the thermochemical properties of the radicals, formed by abstraction of $\mathrm{H}$ atom from these two components, are still unknown.

The reactions of $\mathrm{H}$ atom transfer from substrate to the radicals are ones of the most important processes of decomposition and oxidation of organic compounds during their combustion. In many cases, the rates of these reactions depend on their thermochemistry. Therefore, the determination of thermochemical properties of radicals is important part of development of mechanism of the combustion of substrates. Thus, the knowledge of the thermochemical properties of radicals, involved in these reactions, can be used for the estimation of effect of these reactions on the whole process, as well as for determination of the temperature effect on it.

In the current study, the structures and thermochemical properties of the radicals, formed by abstraction of $\mathrm{H}$ atom from these two components (Dimethyl phthalate and p-Benzylphenol) of the considered surrogate bio-oil, are optimized and calculated using the B3LYP/6-311++G(d,p)), M06-2X/6-311++G(d,p)) and $\mathrm{RO} / \mathrm{CBS}-4 \mathrm{M}$ quantum mechanical (QM) approaches, as well as using the methodology, proposed in [17, 21].

\section{METHODS AND APPROACHES}

In the present work, the geometries of the considered radicals $(\mathrm{Y})$ were optimized using the DFT (B3LYP/6$311++\mathrm{G}(\mathrm{d}, \mathrm{p})[22]$ and M06-2X6-311++G(d,p) [23]) and composites RO/CBS-4M [24, 25] QM approaches ( corresponded, in the last case, to the $\mathrm{HF} / 3-21 \mathrm{G}^{*}$ (3-21G(d) level of theories)), while, in the last case, the CBS-4M potential energies of these structures, as well as their values of $H^{\circ}{ }_{298.15}, S^{\circ}{ }_{298.15}$ and $G{ }^{\circ}{ }_{298.15}$, were determined using the Møller-Plesset (MPn) correlation energy correction [26-29] (RO/CBS-4M), as well as the CBS extrapolation [30,31]) . The methods used in the present work for the calculations of these values were the same as those used in the previous work [21] for the determination of the thermochemical properties of p-Benzylphenol and Dimethyl phthalate. The more accurate methods (such as CBS-Q, CBS-QB3, Gn, CCSD) for the calculation of $H^{\circ} \mathrm{T}(\mathrm{X})$ values of the considered radicals were not used, due to the limitation of the available computational facilities. The calculations were done using the Gaussian program [32]. 
The values of $\Delta_{\mathrm{f}} H^{\circ}{ }_{298.15}(\mathrm{Y}, \mathrm{CALC} / \mathrm{CORR})_{\text {atom }}$ and $\Delta_{\mathrm{f}} H^{{ }^{\circ}}{ }_{298.15}(\mathrm{Y}, \mathrm{CALC} / \mathrm{CORR})_{\mathrm{REAC}}$ of the radicals were determined, respectively, using the thermochemistry of atomization $\left(\Delta_{\mathrm{r}} H{ }^{\mathrm{o}}{ }_{298.15}(\mathrm{Y})_{\text {atom }}\right)$ and homodesmotic $\left(\Delta_{\mathrm{r}} H^{\circ}{ }_{298.15}(\mathrm{Y})_{\mathrm{REAC}}\right)$ reactions. In the first case, the values of $H^{\mathrm{o}}{ }_{298.15},{ }^{\circ}{ }^{\circ}{ }_{298.15}$ and $G{ }^{\circ}{ }_{298.15}$ of $\mathrm{C}_{(\mathrm{g})}, \mathrm{H}_{(\mathrm{g})}, \mathrm{O}_{(\mathrm{g})}$ and $\mathrm{Y}_{(\mathrm{g})}$, were used for the determination of $\Delta_{\mathrm{r}} \mathrm{H}^{\mathrm{o}}{ }_{298.15}(\mathrm{Y}, \mathrm{CALC})_{\text {atom. These values }}$ of $\Delta_{\mathrm{r}} H^{\circ}{ }_{298.15}(\mathrm{Y}, \mathrm{CALC})_{\text {atom }}$ were corrected to the values of $\Delta_{\mathrm{r}} H^{\circ}{ }_{298.15}(\mathrm{Y}, \mathrm{CORR})_{\text {atom }}$ using the linear dependencies ( $=\mathrm{A}+\mathrm{B} \times \Delta_{\mathrm{r}} H^{\circ}{ }^{\circ}{ }_{298.15}(\mathrm{Y}, \mathrm{CALC})_{\text {atom }}$ ), determined previously [17,21], between the tabulated values of $\Delta_{\mathrm{r}} H^{\circ}{ }_{298.15}(\mathrm{X}, \mathrm{TAB})$ atom $\left(\right.$ where $\left.\mathrm{X}=\mathrm{C}_{\mathrm{n}} \mathrm{H}_{\mathrm{m}} \mathrm{O}_{\mathrm{p}}(\mathrm{n}, \mathrm{m}, \mathrm{p})\right)$ and the calculated values of $\Delta_{\mathrm{r}} H$ ${ }^{\circ}{ }_{298.15}$ (X, CALC) atom. The compounds (X) and their tabulated values of $\Delta_{\mathrm{f}} H^{\circ}{ }_{298.15}(\mathrm{X}$, TAB), as well as their calculated values of $H^{\circ}{ }_{298.15}$ (X, CALC), used for the determination of these dependencies, are reported in SI, Note 1 (in bold, when several values is available) and in work [21]. Both the aromatic molecules and radicals were mainly used for the determination of the mentioned correction dependencies.

The corrected values of $\Delta_{\mathrm{r}} H^{\circ}{ }^{\mathrm{o}}{ }_{298.15}(\mathrm{Y}, \mathrm{CORR})$ atom and the tabulated values of $\Delta_{\mathrm{f}} H^{\circ}{ }_{298.15}\left({ }^{3} \mathrm{C}, \mathrm{TAB}\right), \Delta_{\mathrm{f}} H$ ${ }^{\circ}{ }_{298.15}\left({ }^{3} \mathrm{O}, \mathrm{TAB}\right)$ and $\Delta_{\mathrm{f}} H^{\circ}{ }_{298.15}(\mathrm{H}, \mathrm{TAB})$ [33] (SI, Note 1$)$ were used for the determination of the values of $\Delta_{\mathrm{f}} H^{\circ}{ }_{298.15}(\mathrm{Y}, \mathrm{CORR})_{\text {atom. }}$. The errors introduced by the calculated values of the $H^{\mathrm{o}}{ }_{298.15}$ of atoms were considered insignificant $[21,34,35]$. The effects of isotopes and isomers on the thermochemical values were not considered. Thus, in the last case, the effect of the less thermochemically favorable structures on the integral values of $\Delta_{\mathrm{f}} \mathrm{H}^{\mathrm{o}}{ }_{298.15}(\mathrm{Y})$ was considered not exceeding $2-3 \mathrm{~kJ} / \mathrm{mol}$ [36]. This is due to the low contribution of the value of the $T \times \Delta_{\mathrm{r}} S^{\circ}{ }_{298.15}$ of their isomerization reactions to the value of the equilibrium constant at $T=298.15 \mathrm{~K}$ and to the exponential dependence of the value of equilibrium constant upon corresponding value of $\Delta_{\mathrm{r}} \mathrm{H}^{\mathrm{o}}{ }_{298.15}$.

The alternative values of $\Delta_{\mathrm{f}} H^{\circ}{ }^{\mathrm{o}}{ }_{298.15}(\mathrm{Y}, \mathrm{CALC})_{\mathrm{REAC}}$ and $\Delta_{\mathrm{f}} H^{{ }^{\circ}}{ }_{298.15}(\mathrm{Y}, \mathrm{CORR})_{\mathrm{REAC}}$ of the considered compounds were calculated using the B3LYP/6-311++G(d,p), M06-2X/6-311++G(d,p) and RO/CBS-4M thermochemistry of the homodesmotic reactions $\left(\Delta_{\mathrm{r}} H^{\mathrm{o}}{ }_{298.15}(\mathrm{Y}, \mathrm{CALC})_{\text {REAC }}\right)$. The tabulated values of $\Delta_{\mathrm{f}} H$ ${ }^{\circ}{ }_{298.15}(\mathrm{X}, \mathrm{TAB})[33,37]$ of the components of the homodesmotic reactions, used for these calculations, were compiled in $[17,21](S I$, Note 1$)$. The values of $\Delta_{\mathrm{r}} H^{{ }^{\circ}}{ }_{298.15}(\mathrm{Y}, \mathrm{CORR})_{\mathrm{REAC}}$ were determined by conversion of the calculated values of $\Delta_{\mathrm{r}} H^{\mathrm{o}}{ }_{298.15}(\mathrm{Y}, \mathrm{CALC})_{\mathrm{REAC}}$ using the correction dependencies, reported previously for the thermochemistry of 19 homodesmotic reactions $[17,21]$.

The accuracies of B3LYP/6-311++G(d,p), M06-2X/6-311++G(d,p) and RO/CBS-4M approaches, used for the calculation of the values of $\Delta_{\mathrm{r}} H^{\circ}{ }_{298.15}(\mathrm{Y}, \mathrm{CALC})_{\text {atom }}$ and $\Delta_{\mathrm{r}} H^{\circ}{ }_{298.15}(\mathrm{Y}, \mathrm{CALC})_{\mathrm{REAC}}$ of considered aromatic radicals, were determined using the root mean squared error (RMSE), calculated previously [17, 21] on the basis of the tabulated and theoretical values of $\Delta_{\mathrm{r}} H^{\circ}{ }_{298.15}(\mathrm{X})$ defined, respectively, for the atomization and homodesmotic reactions. For each used quantum mechanical approach, the uncertainties of the corrected values of $\Delta_{\mathrm{r}} H^{{ }^{\circ}}{ }_{298.15}(\mathrm{Y}, \mathrm{CORR})_{\text {atom }}$ and $\Delta_{\mathrm{f}} H^{{ }^{\circ}}{ }_{298.15}(\mathrm{Y}, \mathrm{CORR})_{\text {atom }}$, as well as of $\Delta_{\mathrm{r}} H$ ${ }^{\circ}{ }_{298.15}(\mathrm{Y}, \mathrm{CORR})_{\mathrm{REAC}}$ and $\Delta_{\mathrm{f}} H^{{ }^{\circ}}{ }_{298.15}(\mathrm{Y}, \mathrm{CORR})_{\mathrm{REAC}}$, were accepted equal to three values of standard error (SE), reported for the correction dependencies of $\mathrm{X}$.

The most consistent and accurate values of $\Delta_{\mathrm{f}} H^{\circ}{ }_{298.15}(\mathrm{Y}, \mathrm{CORR})_{\text {atom }}$ and $\Delta_{\mathrm{f}} H^{\circ}{ }_{298.15}(\mathrm{Y}, \mathrm{CORR})_{\mathrm{REAC}}$ were determined using the $99.7 \%$ confidence intervals of these values, calculated using the different $\mathrm{QM}$ approaches. In this case, the values of 3SE, corresponded to $99.7 \%$ confidence interval of considered correction dependencies, were used as the uncertainty for the corrected values of $\Delta_{\mathrm{f}} H^{\circ}{ }_{298.15}(\mathrm{Y}, \mathrm{CORR})_{\text {atom }}$ or $\Delta_{\mathrm{f}} H$ ${ }^{\circ}{ }_{298.15}(\mathrm{Y}, \mathrm{CORR})_{\text {REAC. }}$. These uncertainties, calculated using the different QM approaches, were united for each Y. For this, the crossing area, which was common for the considered $99.7 \%$ confidence intervals of the values of $\Delta_{\mathrm{f}} H^{\circ}{ }^{\circ}{ }_{298.15}(\mathrm{Y}, \mathrm{CORR})_{\text {atom }}( \pm 3 \mathrm{SE})$ or $\Delta_{\mathrm{f}} H^{\circ}{ }^{\circ} 298.15(\mathrm{Y}, \mathrm{CORR})_{\mathrm{REAC}}( \pm 3 \mathrm{SE})$, calculated using all quantum mechanical approaches, was determined. The size of this area was considered as the 99.4-99.7\% confidence interval (6SE) [21] for the values of $\Delta_{\mathrm{f}} H^{\circ}{ }^{\circ}{ }_{298.15}(\mathrm{Y}, \mathrm{CORR})_{\text {MEAN }}$ or $\Delta_{\mathrm{f}} H^{\circ}{ }_{298.15}(\mathrm{Y}$, CORR) REACMEAN. The last values were determined as the mean of the upper and lower limits of this common crossing area [17, 21].

Since, the upper and the lower limits of this crossing area were defined only by the uncertainty ranges of one or two of all those values of $\Delta_{\mathrm{f}} H^{{ }^{\circ}}{ }_{298.15}(\mathrm{Y}, \mathrm{CORR})_{\text {atom }}$ or $\Delta_{\mathrm{f}} H^{{ }^{\circ}}{ }_{298.15}(\mathrm{Y}, \mathrm{CORR})_{\mathrm{REAC}}$, calculated using the considered QM approaches for each Y, then the values of their uncertainties were corresponded to 99.4-99.7\% 
confidential interval and were similar or close to the value of 3SE.

The values of uncertainties of $\Delta_{\mathrm{f}} H{ }^{\circ}{ }_{298.15}(\mathrm{Y}, \mathrm{CORR})_{\text {MEAN }}$ and $\Delta_{\mathrm{f}} H^{\circ}{ }_{298.15}(\mathrm{Y}, \mathrm{CORR})_{\text {REACMEAN }}$ were compared, and their most accurate values were recommended as the most reliable and were used in the present work for the determination of the temperature dependencies of $\Delta_{\mathrm{f}} H^{\mathrm{o}_{\mathrm{T}}}(\mathrm{Y}, \mathrm{CORR})$.

Multireferences calculations, successfully applied for the determination of the bonds dissociation energies of the several components of bio-oil/diesel previously [38 - 40], were not considered in the present work. It was assumed that the underestimation of the contribution of static (electronic) correlation introduces the systematic error to the thermochemistry of the atomization and homodesmotic reactions. As a result, the contribution of the static correlation effect to uncertainty was minimized due to the considered correction dependencies.

The results of QM calculations were also used for the determination of the values of $S{ }^{\circ}{ }_{298.15}(\mathrm{Y}$, CALC) $=\left(H^{\circ}{ }^{\circ} 298.15(\mathrm{Y})-G{ }^{\circ}{ }_{298.15}(\mathrm{Y})\right) / 298.15$. The values $S{ }^{\circ}{ }_{298.15}(\mathrm{Y}, \mathrm{CALC})$, calculated using the B3LYP and CBS-4M QM approaches, were corrected using the correction dependencies, reported in [17]. The correction dependence for the M062X/6-311++G(d,p) approach was determined in the present work for the list of compounds similar those, used previously for results of B3LYP and CBS-4M calculations. The using of the correction dependencies, in this case, was need for taking into account the contribution of the internal rotation part of entropy [36], not calculated in the present study, as well as to the determination the uncertainty of these calculations. The corrected values of $S{ }^{\circ}{ }_{298.15}(\mathrm{Y}, \mathrm{CORR})$ were used as their recommended values. The values of $2 \mathrm{SE}$, determined using the correction dependencies, were considered as the uncertainties for the values of $S{ }^{\circ}{ }_{298.15}(\mathrm{Y}, \mathrm{CORR})$.

The accuracy of calculations of vibration frequencies for each of QM approaches was determined from the comparison of the measured [33] and calculated IR spectra, with and without scaling factors. The QM approach, predicted the most accurate values of vibration frequencies of these compounds, was used for determination of the values of $S{ }^{\circ}{ }_{298.15}(\mathrm{Y}, \mathrm{CALC})$ and temperature dependencies of their thermochemical properties, using the ChemRate program [41]. In this case, the scaling factor, recommended by the NIST computational chemistry comparison and benchmark database [42], was used for the correction of the calculated vibration frequencies.

\section{RESULTS AND DISCUSSION}

\subsection{Structures of $Y$ radicals.}

In the present work, the structures of radicals, formed by the abstraction of $\mathrm{H}$ atom from the Dimethyl phthalate (1C-12C) and p-Benzylphenol (1D-21D), are optimized using the RO/CBS-4M (at HF/3-21G* level of theory), M06-2X/6-311++G(d,p) and B3LYP/6-311++G(d,p) approaches. Their optimized structures and the main geometry parameters, determined using the CBS- $4 \mathrm{M}$ calculations, are reported in Table 1. The most thermochemically favorable structures, optimized using the B3LYP/6-311++G(d,p), M06-2X/6$311++\mathrm{G}(\mathrm{d}, \mathrm{p})$ and ROCBS-4M approaches, are presented, respectively, in SI, Notes 2 (Table $A$ and B) and 3 .

Table 1. The structures (bond length ( $b l)$ in nm.) and values of $H^{\circ}{ }_{0}, H^{\circ}{ }_{298.15}$ and $G{ }^{\circ}{ }_{298.15}$ (in Hartree) of $\mathrm{CH}_{3} \mathrm{OC}(\mathrm{O}) \mathrm{C}_{6} \mathrm{H}_{4}(\mathrm{O}) \mathrm{COCH}_{2}(1 \mathrm{C}-13 \mathrm{C})$ and $\mathrm{C}_{6} \mathrm{H}_{5} \mathrm{CHC}_{6} \mathrm{H}_{4} \mathrm{OH}(1 \mathrm{D}-9 \mathrm{D})$, optimized and determined using the CBS-4M approach.

\begin{tabular}{|c|c|}
\hline $1 \mathrm{C} H^{\mathrm{o}}{ }_{0}(1 \mathrm{C})=-686.374556 H^{\mathrm{o}}{ }_{298.15}(1 \mathrm{C})=-686.359911 G^{\mathrm{o}}{ }_{298.15}(1 \mathrm{C})=-686.416399$ & $2 \mathrm{C} H_{0}^{\circ}(2 \mathrm{C})=-686.374329 H^{\circ}$ \\
\hline $4 \mathrm{C} H^{\mathrm{o}}{ }_{0}(4 \mathrm{C})=-686.372791 \mathrm{H}^{\mathrm{o}}{ }_{298.15}(4 \mathrm{C})=-686.358159 G^{\mathrm{o}}{ }_{298.15}(4 \mathrm{C})=-686.414614$ & $5 \mathrm{C} H_{0}^{\mathrm{o}}(5 \mathrm{C})=$ \\
\hline $7 \mathrm{C} H^{\mathrm{o}}{ }_{0}(7 \mathrm{C})=-686.351228 H^{\mathrm{o}}{ }_{298.15}(7 \mathrm{C})=-686.336482 G^{\mathrm{o}}{ }_{298.15}(7 \mathrm{C})=-686.393725$ & $8 \mathrm{C} H^{\mathrm{o}}{ }_{0}(8 \mathrm{C})=-686.351394 H$ \\
\hline $10 \mathrm{C} H^{\mathrm{o}}{ }_{0}(10 \mathrm{C})=-686.350641 H^{\mathrm{o}}{ }_{298.15}(10 \mathrm{C})=-686.335886 G^{\mathrm{o}}{ }_{298.15}(10 \mathrm{C})=-686.393155$ & $11 \mathrm{C} H^{\circ}{ }_{0}(11 \mathrm{C})=-686.349287 I$ \\
\hline $1 \mathrm{D} H_{0}^{\mathrm{o}}(1 \mathrm{D})=-576.275792 H^{\mathrm{o}}{ }_{298.15}(1 \mathrm{D})=-576.263125 G^{\mathrm{o}}{ }_{298.15}(1 \mathrm{D})=-576.314688$ & $2 \mathrm{D} H_{0}^{\circ}(2 \mathrm{D})=-576.275511 I$ \\
\hline $4 \mathrm{D} H_{0}^{\mathrm{o}}(4 \mathrm{D})=-576.224107 H^{\mathrm{o}}{ }_{298.15}(4 \mathrm{D})=-576.211552 G^{\mathrm{o}}{ }_{298.15}(4 \mathrm{D})=-576.264506$ & $5 \mathrm{D} H^{\circ}{ }_{0}(5 \mathrm{D})=-576.222070 H^{\circ}$ \\
\hline $7 \mathrm{D} H_{0}^{\mathrm{o}}(7 \mathrm{D})=-576.220702 H^{\mathrm{o}}{ }_{298.15}(7 \mathrm{D})=-576.207909 G^{\mathrm{o}}{ }_{298.15}(7 \mathrm{D})=-576.261547$ & $8 \mathrm{D} H_{0}^{\mathrm{o}}(8 \mathrm{D})=-576.219901 H^{\circ}$ \\
\hline
\end{tabular}




\begin{tabular}{|c|c|}
\hline $1 \mathrm{C} H_{0}^{\circ}(1 \mathrm{C})=-686.374556 H^{\mathrm{o}}{ }_{298.15}(1 \mathrm{C})=-686.359911 G^{\mathrm{o}}{ }_{298.15}(1 \mathrm{C})=-686.416399$ & $2 \mathrm{C} H_{0}^{\circ}(2 \mathrm{C})=-686.374329 H^{\circ}$ \\
\hline $10 \mathrm{D} H^{\mathrm{o}}{ }_{0}(10 \mathrm{D})=-576.219762 H^{\mathrm{o}}{ }_{298.15}(10 \mathrm{D})=-576.207000 G^{\mathrm{o}}{ }_{298.15}(10 \mathrm{D})=-576.260425$ & $11 \mathrm{D} H_{0}^{\mathrm{o}}(11 \mathrm{D})=-576.219758 I$ \\
\hline $13 \mathrm{D} H^{\mathrm{o}}{ }_{0}(13 \mathrm{D})=-576.219436 H^{\mathrm{o}}{ }_{298.15}(13 \mathrm{D})=-576.206645 G^{\mathrm{o}}{ }_{298.15}(13 \mathrm{D})=-576.260350$ & $14 \mathrm{D} H_{0}^{\mathrm{o}}(14 \mathrm{D})=-576.219423$ \\
\hline $16 \mathrm{D} H^{\mathrm{o}}{ }_{0}(16 \mathrm{D})=-576.218815 H^{\mathrm{o}}{ }_{298.15}(16 \mathrm{D})=-576.205991 G^{\mathrm{o}}{ }_{298.15}(16 \mathrm{D})=-576.259871$ & $17 \mathrm{D} H_{0}^{\mathrm{o}}(17 \mathrm{D})=-576.218743$ \\
\hline $19 \mathrm{D} H^{\mathrm{o}}{ }_{0}(19 \mathrm{D})=-576.217549 \mathrm{H}^{\mathrm{o}}{ }_{298.15}(19 \mathrm{D})=-576.204725 G^{\mathrm{o}}{ }_{298.15}(19 \mathrm{D})=-576.258328$ & $20 \mathrm{D} H_{0}^{\mathrm{o}}(20 \mathrm{D})=-576.216116$ \\
\hline $1 \mathrm{~K} H_{0}^{\circ}(1 \mathrm{~K})=-686.384766 H^{\mathrm{o}}{ }_{298.15}(1 \mathrm{~K})=-686.370480 G^{\mathrm{o}}{ }_{298.15}(1 \mathrm{~K})=-686.426044$ & $2 \mathrm{~K} H_{0}^{\mathrm{o}}(2 \mathrm{~K})=-686.384698 I$ \\
\hline $2 \mathrm{~L} H_{0}^{\mathrm{o}}(2 \mathrm{~L})=-576.275867 H^{\mathrm{o}}{ }_{298.15}(2 \mathrm{~L})=-576.263210 G^{\mathrm{o}}{ }_{298.15}(2 \mathrm{~L})=-576.314715$ & $3 \mathrm{~L} H_{0}^{\circ}(3 \mathrm{~L})=-576.275711 H^{\circ}{ }_{2}$ \\
\hline
\end{tabular}

As can be seen, the significant difference between the geometries of the considered radicals, optimized using the restricted and unrestricted open shell wavefunctions, is not observed for the products of $\mathrm{H}$ atom abstraction from both the Dimethyl phthalate and p-Benzylenephenol. Thus, the integral differences between the bond lengths $(b l)$ of structures, optimized using the CBS-4M and ROCBS-4M, vary from zero (for the structure $2 \mathrm{C}, 1 \mathrm{D}, 2 \mathrm{D}$ and $3 \mathrm{D}$ ) to 0.1 (for the structure $4 \mathrm{C}$ ) $\AA$. At the same time, the discrepancy between the values of $H^{\circ}{ }_{298.15}$, determined using these two approaches for the most thermochemically favorable structures (1C-4C, 1D-3D), is not observed only in the case of the structures 2C, 1D-3D. In all other cases, the values of $H^{\circ}{ }_{298.15}$, calculated using the open shell configuration, are nearly 0.004 Hartree ([?] $\left.10 \mathrm{~kJ} / \mathrm{mol}\right)$ lower those, determined using the ROCBS-4M approach (SI, Note 3 ).

This discrepancy could be attributed to the small difference between the optimized geometries of these structures, which could be attributed to the spin contamination of wavefunctions [43], observed in the case of the CBS-4M calculations of the structures 1C, 3C, 4C. From this point of view, the ROCBS-4M structures $1 \mathrm{C}, 3 \mathrm{C}, 4 \mathrm{C}$ could be considered as the most reliable, while, the structure $2 \mathrm{C}$ as the less important or thermochemically unstable, compared to its conformers. The last statement partially agree with the results of B3LYP/6-311++G(d,p) calculations, for which the spin contamination of wavefunctions is not observed. Thus, the formation of the structure $2 \mathrm{C}$, similar those determined using the CBS-4M approach (Table 1 and SI, Note 3 ), is not predicted by the B3LYP/6-311++G(d,p) (SI, Note 2, Table A), as well as by the UHF/6-311++G(d,p) (SI, Note 4 ) and B3LYP/aug-cc-pVDT (not presented) calculations.

However, the optimization of this structure using the same functional and basis sets (B3LYP/CBSB7 (SI, Note 5 ), B3LYP/6-31G(d,p), B3LYP/6-311G(d,p) and B3LYP/cc-pVDT), but excluding diffuse function, on the contrary, predicts the formation of structure $2 \mathrm{C}$ similar those, reported in Table 1 and SI, Note 3 . Since, the resulting wavefunctions, determined in these calculations, are not spin contaminated, then the mentioned discrepancy between the existence of $2 \mathrm{C}$ structure, predicted using the B3LYP and UHF approaches, is rather must be attributed to the using of the diffuse functions, and not to the spin contamination, as it is assumed initially. As a result, it can be concluded, that the difference between the results of CBS-4M and ROCBS-4M approaches, in context of the structure $2 \mathrm{C}$, is not related to the difference observed between the results of B3LYP calculations, performed with and without using the diffuse functions. Moreover, the values of RMSE, determined for the X compounds using the CBS-4M (RMSE $=31.4 \mathrm{~kJ} / \mathrm{mol}[21])$ and ROCBS-4M (RMSE $=47.1 \mathrm{~kJ} / \mathrm{mol}[21]$ ) approaches demonstrate that the accuracy of determination of $\Delta_{\mathrm{r}} H^{\circ}{ }_{298.15}(\mathrm{X})$ is higher in the first case, despite of the spin contamination of wavefunctions.

The mentioned effect of diffuse function on the optimized geometry of studied radical is also depending on the used QM approach. Thus, the formation of structure $2 \mathrm{C}$, similar those reported in Table 1 and SI, Note 3 , is supported by the results of M06-2X/6-311++G(d,p) (SI, Note 2 , Table B), M06-2X/6-31G(d,p) and

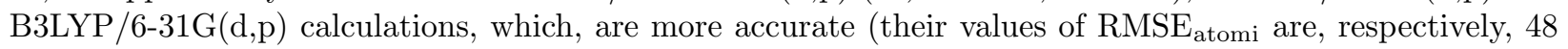
[21], 25.7 and $19.5 \mathrm{~kJ} / \mathrm{mol}[44])$ than those (=90 kJ/mol [21]), determined using the B3LYP/6-311++G(d,p) approach, as well as by the results of MP2(full)/6-311++G(d,p) and B3LYP-GD3/6-311++G(d,p) calculations, included, in the last case, the empirical D3 version of Grimme's dispersion. As a result, the observed discrepancy, most probably, must be attributed to the accuracy of the used QM approaches, particularly, for the calculations of the long distance interactions between the atoms. From this point of view, the structures $2 \mathrm{C}$, optimized using the M06-2X/6-311++G(d,p), MP2/6-311++G(d,p) and B3LYP-GD3/6-311++G(d,p) approaches, are look like more reliable, than those, determined by the B3LYP/6-311++G(d,p) calculations. 
The concluded higher accuracy of $\mathrm{M} 06-2 \mathrm{X} / 6-311++\mathrm{G}(\mathrm{d}, \mathrm{p})$ for the geometry optimization of considered radicals, is also indicating that the CBS-4M geometry of structures $1 \mathrm{C}, 3 \mathrm{C}$ and $4 \mathrm{C}$ must be slightly more reliable in comparison with the results of ROCBS-4M calculations. Thus, the geometries of the radicals, optimized using the M06-2X/6-311++G(d,p) approach, are slightly closer those, determined using the CBS$4 \mathrm{M}$ calculations, than using the ROCBS-4M. This is also in agreement with the values of RMSE, reported previously for the CBS-4M and ROCBS-4M approaches [21]. The last observation is indicating that the negative effect of spin contamination of wavefunction on the accuracy of calculation of potential energy and determination of geometry of the considered radicals is less significant than the effect on them of the restrictions, used in the ROSBS-4M approach.

On the contrast to the radicals formed from Dimethyl phthalate, the optimized structures of the radicals formed by the abstraction of $\mathrm{H}$ atom from p-Benzylphenol are consistent for all considered QM approaches. Thus, the integral difference between the values of $b l$ of these structures, optimized using the considered QM approaches, is below $0.13 \AA$ and is mainly due to the length of $\mathrm{C}-\mathrm{H}$ bonds. Moreover, this difference can even be 2-3 times smaller, because the used values of the bond lengths are rounded with the accuracy of $0.01 \AA$.

As can be seen, in the case of Dimethyl phthalate, the most thermochemically favorable pathway of $\mathrm{H}$ atom abstraction is due to the dissociation of $\mathrm{C}-\mathrm{H}$ bond of the ending methyl groups (structures 1C, 3C and $4 \mathrm{C}$ ). This conclusion is correct for the results, determined using all the considered QM approaches. The same conclusions are also applicable for the radicals formed by the abstraction of $\mathrm{H}$ atom from the p-Benzylenephenol. Thus, the dissociation of $\mathrm{C}-\mathrm{H}$ bond of the methylene group (structures 1D, 2D) is also the most thermochemically favorable pathway for the considered reactions. This route of $\mathrm{H}$ atom abstraction is even more thermochemically favorable than the formation of phenoxy radical (structure 3D), concluded previously as the best for the products of $\mathrm{H}$ atom abstraction from the different substituted phenols [17] with the single aromatic ring. The difference between the results of this and previous work is due to the conjugation of the unpaired electron, localized at $\mathrm{CH}$ group, with $\pi$ electrons of two aromatic rings of the p-Benzylenephenol, instead of the single ring of the substituted phenols, considered in [17].

This explanation is supported by the almost planar structures of these radicals (1D, 2D), in contrast with the nearly orthogonal position of aromatic rings in the structure 3D (Table 1). The detailed description of these structures is presented in SI, Note 6.

The thermochemical properties of radicals, produced by abstraction of $\mathrm{H}$ atom from meta and para isomers of Dimethyl phthalate, as well as from ortho and meta isomers of p-Benzylphenol, are out of scope of this work. However, the values of $H^{\circ}{ }_{298.15}$ for the several structures, expected to be the most thermochemically favorable (due to the higher thermochemical stability of these isomers [21]), are also determined. In this case, the structures of the possible conformers of the considered radicals and their values of potential energy are determined using the CBS-4M calculations. The structures of the most thermochemically stable of these conformers $(1 \mathrm{~K}, 2 \mathrm{~K}, 1 \mathrm{~L}-4 \mathrm{~L})$ are presented in Table 1 . The values of $\Delta_{\mathrm{f}} H^{{ }^{\circ}}{ }_{298.15}(\mathrm{Y})_{\text {atom }}$ of these radicals are also calculated in the present work using the thermochemistry of atomization reactions.

\subsection{Thermochemical properties of the radicals}

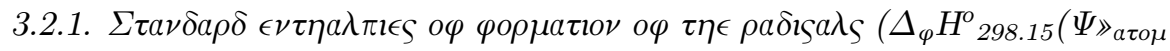

The values of $H^{\circ}{ }_{298.15}(\mathrm{Y})$ of the structures of radicals, considered in the present work (Table 1), as well as their calculated values of the standard enthalpies of atomization $\left(\Delta_{\mathrm{r}} \mathrm{H}^{\circ}{ }_{298.15}(\mathrm{Y}, \mathrm{CALC})_{\text {atom }}\right)$, have used for the determination of $\Delta_{\mathrm{f}} H^{\mathrm{O}}{ }_{298.15}(\mathrm{Y}, \mathrm{CALC})_{\text {atom }}$. The value of $\Delta_{\mathrm{r}} \mathrm{H}^{\mathrm{O}}{ }_{298.15}(\mathrm{Y}, \mathrm{CALC})_{\text {atom }}$, calculated using the different QM approaches, are presented in Table 2.

Table 2. The values of $-\Delta_{\mathrm{r}} H^{\mathrm{o}}{ }_{298.15}(\mathrm{Y}, \mathrm{CALC})_{\text {atom }}$ and $-\Delta_{\mathrm{r}} H^{\mathrm{o}}{ }_{298.15}(\mathrm{Y}, \mathrm{CORR})_{\text {atom }}$ of atomization reactions, determined using the different $\mathrm{QM}$ approaches and corresponded them correction dependencies.

\begin{tabular}{lllll}
\hline $\mathrm{Y}$ & $-\Delta_{\mathrm{r}} H^{\mathrm{o}}{ }_{298.15}(\mathrm{Y}, \mathrm{CALC})_{\text {atom }}, \mathrm{kJ} / \mathrm{mol}$ & $-\Delta_{\mathrm{r}} H^{\mathrm{o}}{ }_{298.15}(\mathrm{Y}, \mathrm{CALC})_{\text {atom }}, \mathrm{kJ} / \mathrm{mol}$ & $-\Delta_{\mathrm{r}} H^{\mathrm{o}}{ }_{298.15}(\mathrm{Y}, \mathrm{CALC})_{\text {atom }}, \mathrm{kJ} / \mathrm{mol}$ & - \\
\hline $\mathrm{B} 3 \mathrm{LYP}$ & $\mathrm{M} 06-2 \mathrm{X}$ & $\mathrm{CBS}-4 \mathrm{M}$ & $\mathrm{R}$
\end{tabular}




\begin{tabular}{|c|c|c|c|}
\hline Y & $-\Delta_{\mathrm{r}} H^{\mathrm{o}}{ }_{298.15}(\mathrm{Y}, \mathrm{CALC})_{\text {atom }}, \mathrm{kJ} / \mathrm{mol}$ & $-\Delta_{\mathrm{r}} H^{\mathrm{o}}{ }_{298.15}(\mathrm{Y}, \mathrm{CALC})_{\text {atom }}, \mathrm{kJ} / \mathrm{mol}$ & $-\Delta_{\mathrm{r}} H^{\mathrm{o}}{ }_{298.15}(\mathrm{Y}, \mathrm{CALC})_{\text {atom }}, \mathrm{kJ} / \mathrm{mol}$ \\
\hline $1 \mathrm{C}$ & -10350.2 & -10461.5 & -10566.6 \\
\hline $2 \mathrm{C}$ & -10350.1 & -10453.4 & -10566.6 \\
\hline $3 \mathrm{C}$ & -10350.1 & -10458.6 & -10562.8 \\
\hline $4 \mathrm{C}$ & -10348.7 & -10457.1 & -10562 \\
\hline $5 \mathrm{C}$ & -10286.8 & -10405.0 & -10507.6 \\
\hline $6 \mathrm{C}$ & -10287.1 & -10401.7 & -10505.9 \\
\hline $7 \mathrm{C}$ & -10283.2 & -10399.4 & -10505.1 \\
\hline $8 \mathrm{C}$ & -10287.6 & -10404.1 & -10505.6 \\
\hline $9 \mathrm{C}$ & -10287.4 & -10403.9 & -10505.1 \\
\hline $10 \mathrm{C}$ & -10284.4 & -10398.9 & -10503.6 \\
\hline $11 \mathrm{C}$ & -10284.4 & -10396.5 & -10500.2 \\
\hline $12 \mathrm{C}$ & -10287.6 & -10399.4 & -10499.9 \\
\hline 1D & -11658.7 & -11756.0 & -11922.4 \\
\hline $2 \mathrm{D}$ & -11658.7 & -11755.8 & -11921.6 \\
\hline $3 \mathrm{D}$ & -11646.3 & -11740.7 & -11902.6 \\
\hline $4 \mathrm{D}$ & -11525.2 & -11639.9 & -11787 \\
\hline $5 \mathrm{D}$ & -11522.8 & -11637.9 & -11781.6 \\
\hline $6 \mathrm{D}$ & -11525.4 & -11639.1 & -11777.7 \\
\hline 7D & -11525.7 & -11639.4 & -11777.4 \\
\hline $8 \mathrm{D}$ & -11523.3 & -11636.5 & -11775.3 \\
\hline 9D & -11522.7 & -11635.9 & -11775.1 \\
\hline 10D & -11525.0 & -11639.6 & -11775 \\
\hline 11D & -11524.9 & -11639.5 & -11775 \\
\hline $12 \mathrm{D}$ & -11525.2 & -11639.8 & -11774.5 \\
\hline $13 \mathrm{D}$ & -11525.7 & -11639.3 & -11774.1 \\
\hline 14D & -11525.4 & -11639.5 & -11774 \\
\hline $15 \mathrm{D}$ & -11525.7 & -11638.0 & -11772.8 \\
\hline $16 \mathrm{D}$ & -11524.5 & -11637.8 & -11772.4 \\
\hline 17D & -11525.4 & -11638.1 & -11772.3 \\
\hline $18 \mathrm{D}$ & -11522.8 & -11637.9 & -11769.7 \\
\hline 19D & -11515.7 & -11629.4 & -11769 \\
\hline $20 \mathrm{D}$ & -11515.4 & -11629.2 & -11765.3 \\
\hline 21D & -11524.5 & -11638.0 & -11741.9 \\
\hline $1 \mathrm{~K}$ & -10380.5 & -10484.2 & -10594.4 \\
\hline $2 \mathrm{~K}$ & -10379.3 & -10485.4 & -10592.2 \\
\hline 1L & -11658.3 & -11755.9 & -11922.6 \\
\hline $2 \mathrm{~L}$ & -11657.7 & -11755.1 & -11922.6 \\
\hline $3 \mathrm{~L}$ & -11657.6 & -11757.5 & -11922.4 \\
\hline $4 \mathrm{~L}$ & -11654.3 & -11758.5 & -11919.8 \\
\hline
\end{tabular}

The values of $\Delta_{\mathrm{r}} H^{{ }^{\circ}}{ }_{298.15}(\mathrm{Y}, \mathrm{CALC})_{\text {atom }}$, presented in Table 2, are determined using the values of $H$ ${ }^{\circ}{ }_{298.15}(\mathrm{Y}), H^{\circ}{ }^{\circ}{ }_{298.15}(\mathrm{C}), H^{\circ}{ }_{298.15}(\mathrm{O})$ and $H^{\circ}{ }_{298.15}(\mathrm{H})$, calculated in this and in the previous works [17, 21]. Their CBS-4M values of $H^{\circ}{ }_{298.15}(\mathrm{Y})$ are reported in Table 1. The M06-2X and B3LYP values of ${ }^{\circ}{ }_{298.15}(\mathrm{Y})$ for the most thermochemically stable structures are presented, respectively, inSI, Note 2 and 3 . The M062X and B3LYP values of $H^{\circ}{ }_{298.15}(\mathrm{C}), H^{\circ}{ }_{298.15}(\mathrm{O})$ and ${ }^{\circ}{ }_{298.15}(\mathrm{H})$ are demonstrated inSI, Note 1 . Their $\mathrm{RO} / \mathrm{CBS}-4 \mathrm{M}$ values can be found in [17].

As can be seen, the values of $\Delta_{\mathrm{r}} H^{{ }^{\circ}}{ }_{298.15}(\mathrm{Y}, \mathrm{CALC})_{\text {atom, }}$, calculated in the present work using the different QM approaches, are not consistent. Thus, for the most thermochemically stable radicals (structures 1C, 
3C, 4C, 1D-3D), the highest differences between their values of $\Delta_{\mathrm{r}} H^{\circ}{ }_{298.15}(\mathrm{Y}$, CALC) atom, observed in the cases of using the CBS-4M and B3LYP/6-311++G(d,p) approaches, reaches $200 \mathrm{~kJ} / \mathrm{mol}$.

Such high differences are mainly due to the values of $\Delta_{\mathrm{r}} H^{\mathrm{o}}{ }_{298.15}$ (X, CALC) atom, calculated using the QM approaches at the low level of theory, assuming the high contribution of the systematic errors to the results of calculations [45-48]. Thus, the more accurate CBS-4M, ROCBS-4M and M06-2X approaches lead, respectively, to the significantly smaller values of $\mathrm{RMSE}_{\text {atomi }}=31.3,47.0$ and $47.8 \mathrm{~kJ} / \mathrm{mol}[17,21]$.

The correction of these values of $\Delta_{\mathrm{r}} H^{\circ}{ }_{298.15}(\mathrm{Y}, \mathrm{CALC})_{\text {atom }}$ according to the dependencies (SI, Note 7 ), reported previously $[17,21]$, decreases significantly the mentioned differences between the values of $\Delta_{\mathrm{r}} H$ ${ }^{\circ}{ }_{298.15}(\mathrm{Y}, \mathrm{CORR})_{\text {atom }}$ (Table 2), determined using the different QM approaches. Thus, the differences between the corrected CBS-4M and ROCBS-4M or M06-2X values of $\Delta_{\mathrm{r}} H^{\circ}{ }_{298.15}(\mathrm{Y}, \mathrm{CORR})_{\text {atom }}$ do not exceed, respectively, 25 and $32 \mathrm{~kJ} / \mathrm{mol}$. The even smaller difference, below $16 \mathrm{~kJ} / \mathrm{mol}$, is observed between those values, calculated using the CBS-4M and B3LYP/6-311++G(d,p) approaches. These values of differences are consistent with the values of $\mathrm{SE}_{\text {atomi }}=8.4(\mathrm{CBS}-4 \mathrm{M}), 9.4(\mathrm{ROCBS}-4 \mathrm{M}), 11.8(\mathrm{~B} 3 \mathrm{LYP})$ and $3.8(\mathrm{M} 06-2 \mathrm{X})$ $\mathrm{kJ} / \mathrm{mol}$, determined using their correction dependencies previously (SI, Note 7 ) [17, 21].

Table 3. The values of $\Delta_{\mathrm{f}} H^{\circ}{ }_{298.15}(\mathrm{Y}, \mathrm{CORR})_{\text {atom }}$, determined using the different QM approaches, as well as their mean values of $\Delta_{\mathrm{f}} H^{\circ}{ }_{298.15}(\mathrm{Y}, \mathrm{CORR})_{\mathrm{MEAN}}$, determined using the upper and lower limits of the common area of the uncertainty ranges of the values of $\Delta_{\mathrm{f}} H^{\circ}{ }_{298.15}(\mathrm{Y}, \mathrm{CORR})_{\text {atom }}$. (The errors correspond to the values of $3 \mathrm{SE}$, determined for the correction dependencies [17, 21] (SI, Note 7 )).

\begin{tabular}{|c|c|c|c|c|c|c|c|}
\hline Y & $\begin{array}{l}\Delta_{\mathrm{f}} H^{\mathrm{o}}{ }_{298.15}(\mathrm{Y}, \\
\mathrm{CORR})_{\text {atom }} \\
\mathrm{kJ} / \mathrm{mol}\end{array}$ & $\begin{array}{l}\Delta_{\mathrm{f}} H^{\mathrm{o}}{ }_{298.15}(\mathrm{Y}, \\
\mathrm{CORR})_{\text {atom }} \\
\mathrm{kJ} / \mathrm{mol}\end{array}$ & $\begin{array}{l}\Delta_{\mathrm{f}} H^{\mathrm{o}}{ }_{298.15}(\mathrm{Y}, \\
\mathrm{CORR})_{\text {atom }} \\
\mathrm{kJ} / \mathrm{mol}\end{array}$ & $\begin{array}{l}\Delta_{\mathrm{f}} H^{\mathrm{O}}{ }_{298.15}(\mathrm{Y}, \\
\mathrm{CORR})_{\text {atom }} \\
\mathrm{kJ} / \mathrm{mol}\end{array}$ & $\begin{array}{l}\Delta_{\mathrm{f}} H^{\mathrm{o}}{ }_{298.15}(\mathrm{Y}, \\
\mathrm{CORR})_{\text {atom }} \\
\mathrm{kJ} / \mathrm{mol}\end{array}$ & $\begin{array}{l}\Delta_{\mathrm{f}} H^{\mathrm{O}}{ }_{298.15}(\mathrm{Y}, \\
\mathrm{CORR})_{\text {atom }} \\
\mathrm{kJ} / \mathrm{mol}\end{array}$ & $\begin{array}{l}\Delta_{\mathrm{f}} H^{\mathrm{o}}{ }_{298.15}(\mathrm{Y} \\
\mathrm{CORR})_{\text {MEAN }} \\
\mathrm{kJ} / \mathrm{mol}\end{array}$ \\
\hline & $\begin{array}{l}\text { B3LYP } \\
( \pm 33.6)\end{array}$ & $\begin{array}{l}\text { M06-2X } \\
( \pm 11.4)\end{array}$ & $\begin{array}{l}\text { CBS-4M } \\
( \pm 25.2)\end{array}$ & $\begin{array}{l}\text { ROCBS-4M } \\
( \pm 27.6)\end{array}$ & Lower & Upper & \\
\hline $1 \mathrm{C}$ & -395.3 & -414.2 & -384.1 & -400.6 & -409.3 & -402.8 & $-406.1 \pm 3$ \\
\hline $2 \mathrm{C}$ & -395.2 & -406.1 & -384.1 & -388.7 & -409.3 & -394.7 & $-402 \pm 7$ \\
\hline $3 \mathrm{C}$ & -395.2 & -411.3 & -380.2 & -397.0 & -405.4 & -399.9 & $-402.6 \pm 3$ \\
\hline $4 \mathrm{C}$ & -393.8 & -409.8 & -379.6 & -395.8 & -404.8 & -398.4 & $-401.6 \pm 3$ \\
\hline $5 \mathrm{C}$ & -330.7 & -357.4 & -325.5 & -351.2 & -350.7 & -346.0 & $-348.4 \pm 3$ \\
\hline $6 \mathrm{C}$ & -331.0 & -354.1 & -323.8 & -345.1 & -349.0 & -342.7 & $-345.9 \pm 3$ \\
\hline $7 \mathrm{C}$ & -327.0 & -351.7 & -323.0 & -345.1 & -348.2 & -340.3 & $-344.2 \pm 4$ \\
\hline $8 \mathrm{C}$ & -331.5 & -356.4 & -323.5 & -348.2 & -348.7 & -345.2 & $-346.9 \pm 2$ \\
\hline $9 \mathrm{C}$ & -331.3 & -356.3 & -322.9 & -347.6 & -348.1 & -344.9 & $-346.5 \pm 2$ \\
\hline $10 \mathrm{C}$ & -328.3 & -351.2 & -321.5 & -342.8 & -346.7 & -339.8 & $-343.2 \pm 3$ \\
\hline $11 \mathrm{C}$ & -328.3 & -348.9 & -318.1 & -338.3 & -343.3 & -337.5 & $-340.4 \pm 3$ \\
\hline $12 \mathrm{C}$ & -331.5 & -351.8 & -317.8 & -341.6 & -343.0 & -340.4 & $-341.7 \pm 1$ \\
\hline 1D & 110.6 & 121.0 & 107.1 & 91.1 & 109.6 & 118.7 & $114.2 \pm 5$ \\
\hline $2 \mathrm{D}$ & 110.7 & 121.3 & 107.8 & 91.2 & 109.9 & 118.8 & $114.4 \pm 4$ \\
\hline $3 \mathrm{D}$ & 123.3 & 136.5 & 126.8 & 142.4 & 125.1 & 149.9 & $136.5 \pm 11$ \\
\hline $4 \mathrm{D}$ & 246.6 & 237.9 & 241.7 & 223.1 & 226.5 & 249.3 & $237.9 \pm 11$ \\
\hline $5 \mathrm{D}$ & 249.1 & 239.9 & 247.0 & 225.5 & 228.5 & 251.3 & $239.9 \pm 11$ \\
\hline $6 \mathrm{D}$ & 246.4 & 238.7 & 250.9 & 225.0 & 227.3 & 250.1 & $238.7 \pm 11$ \\
\hline $7 \mathrm{D}$ & 246.2 & 238.4 & 251.2 & 219.4 & 227.0 & 247.0 & $237.0 \pm 10$ \\
\hline $8 \mathrm{D}$ & 248.6 & 241.3 & 253.2 & 224.9 & 229.9 & 252.5 & $241.3 \pm 11$ \\
\hline 9D & 249.1 & 241.9 & 253.5 & 226.1 & 230.5 & 252.7 & $241.6 \pm 11$ \\
\hline $10 \mathrm{D}$ & 246.8 & 238.2 & 253.5 & 222.9 & 226.8 & 249.6 & $238.2 \pm 11$ \\
\hline $11 \mathrm{D}$ & 246.9 & 238.3 & 253.5 & 218.6 & 226.9 & 246.2 & $236.7 \pm 10$ \\
\hline $12 \mathrm{D}$ & 246.6 & 238.0 & 254.0 & 222.6 & 226.6 & 249.4 & $238.0 \pm 11$ \\
\hline $13 \mathrm{D}$ & 246.1 & 238.5 & 254.5 & 223.7 & 227.1 & 249.9 & $238.5 \pm 11$ \\
\hline $14 \mathrm{D}$ & 246.4 & 238.3 & 254.6 & 224.7 & 226.9 & 249.7 & $238.3 \pm 11$ \\
\hline
\end{tabular}




\begin{tabular}{|c|c|c|c|c|c|c|c|}
\hline Y & $\begin{array}{l}\Delta_{\mathrm{f}} H^{\mathrm{o}}{ }_{298.15}(\mathrm{Y}, \\
\mathrm{CORR})_{\text {atom }} \\
\mathrm{kJ} / \mathrm{mol}\end{array}$ & $\begin{array}{l}\Delta_{\mathrm{f}} H^{\mathrm{o}}{ }_{298.15}(\mathrm{Y}, \\
\mathrm{CORR})_{\text {atom }} \\
\mathrm{kJ} / \mathrm{mol}\end{array}$ & $\begin{array}{l}\Delta_{\mathrm{f}} H^{\mathrm{o}}{ }_{298.15}(\mathrm{Y}, \\
\mathrm{CORR})_{\text {atom }} \\
\mathrm{kJ} / \mathrm{mol}\end{array}$ & $\begin{array}{l}\Delta_{\mathrm{f}} H^{\mathrm{O}}{ }_{298.15}(\mathrm{Y}, \\
\mathrm{CORR})_{\text {atom }} \\
\mathrm{kJ} / \mathrm{mol}\end{array}$ & $\begin{array}{l}\Delta_{\mathrm{f}} H^{\mathrm{O}}{ }_{298.15}(\mathrm{Y}, \\
\mathrm{CORR})_{\text {atom }} \\
\mathrm{kJ} / \mathrm{mol}\end{array}$ & $\begin{array}{l}\Delta_{\mathrm{f}} H^{\mathrm{o}}{ }_{298.15}(\mathrm{Y}, \\
\mathrm{CORR})_{\text {atom }} \\
\mathrm{kJ} / \mathrm{mol}\end{array}$ & $\begin{array}{l}\Delta_{\mathrm{f}} H^{\mathrm{O}}{ }_{298.15}(\mathrm{Y} \\
\mathrm{CORR})_{\text {MEAN }}, \\
\mathrm{kJ} / \mathrm{mol}\end{array}$ \\
\hline $15 \mathrm{D}$ & 246.1 & 239.8 & 255.7 & 225.7 & 228.4 & 252.2 & $239.8 \pm 11$ \\
\hline $16 \mathrm{D}$ & 247.3 & 240.0 & 256.2 & 226.4 & 228.6 & 251.4 & $240.0 \pm 11$ \\
\hline $17 \mathrm{D}$ & 246.4 & 239.7 & 256.3 & 220.9 & 228.3 & 248.5 & $238.4 \pm 10$ \\
\hline $18 \mathrm{D}$ & 249.0 & 239.9 & 258.8 & 225.1 & 228.5 & 251.3 & $239.9 \pm 11$ \\
\hline 19D & 256.3 & 248.4 & 259.5 & 232.8 & 237.0 & 259.8 & $248.4 \pm 11$ \\
\hline $20 \mathrm{D}$ & 256.6 & 248.7 & 263.2 & 232.2 & 238 & 259.8 & $248.9 \pm 11$ \\
\hline $21 \mathrm{D}$ & 247.4 & 239.8 & 286.4 & 226.2 & 228.4 & 251.2 & $239.8 \pm 11$ \\
\hline $1 \mathrm{~K}$ & -426.5 & -437.4 & -412.3 & -416.9 & -437.5 & -426.0 & $-433.8 \pm 6$ \\
\hline $2 \mathrm{~K}$ & -425.2 & -438.6 & -412.1 & -416.9 & -437.3 & -427.2 & $-433.3 \pm 5$ \\
\hline 1L & 110.7 & 120.8 & 106.2 & 89.2 & 109.4 & 116.8 & $113.1 \pm 4$ \\
\hline $2 \mathrm{~L}$ & 111.3 & 121.6 & 106.2 & 90.1 & 110.2 & 117.7 & $113.9 \pm 4$ \\
\hline $3 \mathrm{~L}$ & 111.4 & 119.2 & 106.4 & 91.4 & 107.8 & 119.0 & $113.4 \pm 6$ \\
\hline $4 \mathrm{~L}$ & 114.8 & 118.2 & 109.0 & 93.6 & 106.8 & 121.2 & $114.0 \pm 7$ \\
\hline
\end{tabular}

The corrected values of $\Delta_{\mathrm{f}} H{ }^{\circ}{ }_{298.15}(\mathrm{Y}, \mathrm{CORR})_{\text {atom }}$, determined using the values of $\Delta_{\mathrm{r}} H{ }^{\circ}{ }_{298.15}(\mathrm{Y}$, CORR $)_{\text {atom }}$, calculated in the present work, and the tabulated values of $\Delta_{\mathrm{f}} H^{\circ}{ }_{298.15}(\mathrm{C}, \mathrm{TAB}), \Delta_{\mathrm{f}} H^{\circ}{ }_{298.15}(\mathrm{O}$, TAB) and $\Delta_{\mathrm{f}} H^{\circ}{ }_{298.15}(\mathrm{H}, \mathrm{TAB})($ SI, Note 1 [33]), are presented in Table 3. The reported uncertainties correspond to the values of $3 \mathrm{SE}_{\text {atomi }}(99.7 \%$ confidence interval).

These uncertainties intervals of the values of $\Delta_{\mathrm{f}} \mathrm{H}^{\mathrm{O}}{ }_{298.15}(\mathrm{Y}, \mathrm{CORR})_{\text {atom }}$ are used for the determination of the values of $\Delta_{\mathrm{f}} H^{\circ}{ }_{298.15}(\mathrm{Y}, \mathrm{CORR})_{\mathrm{MEAN}}$, according to the procedure, described in [17, 21]. Thus, the uncertainty ranges of the values of $\Delta_{\mathrm{f}} H^{\circ}{ }_{298.15}(\mathrm{Y}, \mathrm{CORR})_{\text {atom }}$, determined using the different QM approaches for the same structures $(\mathrm{Y})$, are compared one with other. As a result, the lower and upper limit of the values of $\Delta_{\mathrm{f}} H^{\mathrm{o}}{ }_{298.15}(\mathrm{Y}, \mathrm{CORR})_{\text {atom }}$ for the particular structure are determined as the limits of the crossing area (Table 3) of all $99.7 \%$ confidence intervals. By other word, it is assumed that the target value belong simultaneously to $3 \mathrm{SE}$ intervals of all values, determined using the considered QM approaches. This procedure is applied for the each of the considered radicals $(\mathrm{Y})$. The mean values $\left(\Delta_{\mathrm{f}} H^{\circ}{ }_{298.15}(\mathrm{Y}\right.$, CORR) $)_{\text {MEAN }}$ ) of these limits are considered as the most accurate estimate of that values (Table 3), while, the half of the corresponding range as their uncertainty.

Since, the upper and lower limits of the crossing area for each considered structure $\mathrm{Y}$ is defined by the intervals of only one or two of the corrected values of $\Delta_{\mathrm{f}} H^{{ }^{\circ}}{ }_{298.15}(\mathrm{Y}, \mathrm{CORR})_{\text {atom }}$ then the probability of these events, corresponded to the result of the multiplications of the individual probabilities $(0.997,3 \mathrm{SE})$, is equal to $99.7 \%\left(=100 \% * 0.997^{1}\right)$ or $99.4 \%\left(=100 \% * 0.997^{2}\right)$, i.e. [?] 3SE. In this context, the M06-2X approach must be considered as the most accurate among those considered in the present study. Thus, all intervals for the values of $\Delta_{\mathrm{f}} H^{\circ}{ }_{298.15}(\mathrm{Y}, \mathrm{CORR})_{\text {MEAN }}$, reported in Table 3, correspond to one or both values of limits (upper and/or lower), determined for the M06-2X values of $\Delta_{\mathrm{f}} H^{\circ}{ }_{298.15}(\mathrm{Y}, \mathrm{CORR})$.

This conclusion agrees with dependencies (Figures 1 and 2), observed between the values of $\Delta_{\mathrm{f}} H^{\circ}{ }_{298.15}(\mathrm{Y}$, CORR $)_{\text {MEAN }}$ and corresponded them values of $\Delta_{\mathrm{f}} H^{{ }^{\circ}}{ }_{298.15}(\mathrm{Y}, \mathrm{CORR})_{\text {atom }}$, determined using the different QM approaches for the products of $\mathrm{H}$ atom abstraction, respectively, from Dimethyl phthalate and pBenzylphenol.

Figure 1. The dependencies between the values of $\Delta_{\mathrm{f}} H{ }^{\mathrm{o}}{ }_{298.15}(\mathrm{Y}, \mathrm{CORR})_{\mathrm{MEAN}}$ and corresponding them values of $\Delta_{\mathrm{f}} H{ }^{\circ}{ }_{298.15}(\mathrm{Y}, \mathrm{CORR})_{\text {atom }}$, determined using the B3LYP (closed squares, solid line, $=49+1.1 \times \Delta_{\mathrm{f}} H^{\circ}{ }_{298.15}(\mathrm{Y}, \mathrm{CORR})_{\mathrm{MEAN}}$ ), M06-2X (open squares, dot-dashed line, $=-19+0.972 \times \Delta_{\mathrm{f}} H$ ${ }^{\circ}{ }_{298.15}(\mathrm{Y}, \mathrm{CORR})_{\text {MEAN }}$ ), CBS-4M (open circles, dashed line, $\left.=30.1+1.02 \times \Delta_{\mathrm{f}} H^{\circ}{ }_{298.15}(\mathrm{Y}, \mathrm{CORR})_{\text {MEAN }}\right)$ and ROCBS-4M (closed circles, dotted line, $=-46.5+0.867 \times \Delta_{\mathrm{f}} H^{{ }^{\circ}}{ }_{298.15}(\mathrm{Y}, \mathrm{CORR})_{\mathrm{MEAN}}$ ) approaches for the products of abstraction of $\mathrm{H}$ atom from Dimethyl phthalate. 
Figure 2. The dependencies between the values of $\Delta_{\mathrm{f}} H{ }^{\mathrm{o}}{ }_{298.15}(\mathrm{Y}, \mathrm{CORR})_{\mathrm{MEAN}}$ and corresponding them values of $\Delta_{\mathrm{f}} H{ }^{\circ}{ }_{298.15}(\mathrm{Y}, \mathrm{CORR})_{\text {atom }}$, determined using the B3LYP (closed squares, solid line, = $-19.5+1.11 \times \Delta_{\mathrm{f}} H{ }^{\circ}{ }_{298.15}(\mathrm{Y}, \mathrm{CORR})_{\mathrm{MEAN}}$ ), M06-2X (open squares, dot-dashed line, $=-10.8+0.953 \times \Delta_{\mathrm{f}} H$ $\left.{ }^{\circ}{ }_{298.15}(\mathrm{Y}, \mathrm{CORR})_{\mathrm{MEAN}}\right)$, CBS-4M (open circles, dashed line, $\left.=-29.7+1.18 \times \Delta_{\mathrm{f}} H^{\circ}{ }_{298.15}(\mathrm{Y}, \mathrm{CORR})_{\mathrm{MEAN}}\right)$ and ROCBS-4M (closed circles, dotted line, $=-14.1+0.997 \times \Delta_{\mathrm{f}} H{ }^{\circ}{ }_{298.15}(\mathrm{Y}, \mathrm{CORR})_{\mathrm{MEAN}}$ ) approaches for the products of abstraction of $\mathrm{H}$ atom from p-Benzylphenol.

As can be seen the most consistent dependencies are also observed in the case of using the M06-2X approach. Thus, both dependencies, determined using this approach, have the closest values of intercepts and slopes. Moreover, their absolute values of intercepts are closest to zero.

At the same time, in the case of Dimethyl phthalate, the value of slope, closest to the unity, is observed for the CBS-4M dependence, while, in the case of p-Benzylphenol, for the ROCBS-4M dependence. However, the differences between those values and the values, determined using the M06-2X approach, are insignificant, compared to consistency between the dependencies, determined in the last case for Dimethyl phthalate and p-Benzylphenol.

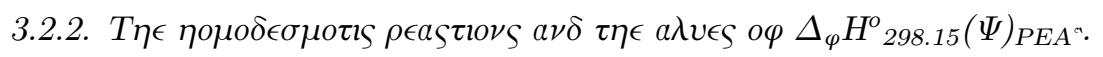

Alternatively, the same compounds (SI, Note 1 ) are used for the determination of the correction dependencies $[17,21]$ and for the calculation of the values of $\Delta_{\mathrm{r}} H^{\circ}{ }_{298.15}(\mathrm{Y}, \mathrm{CALC})_{\mathrm{REAC}}$ of homodesmotic reactions (Table 4).

The homodesmotic reactions, used for the determination of their tabulated values of $\Delta_{\mathrm{r}} H$ ${ }^{\circ}{ }_{298.15}\left(\mathrm{R}_{\mathrm{i}}, \mathrm{TAB}\right)_{\mathrm{REAC}}$, as well as their values of $\Delta_{\mathrm{r}} H^{\mathrm{o}_{298.15}}\left(\mathrm{R}_{\mathrm{i}}, \mathrm{CALC}\right)_{\mathrm{REAC}}$, calculated using different $\mathrm{QM}$ approaches, are reported in $[17,21]$. The accuracy of these calculations, corresponded to RMSE $\mathrm{REACi}_{\mathrm{i}}$, is determined previously $[17,21]$, using the homodesmotic reactions, for which, the thermochemical properties of all components are known (SI, Note 7, Table B ).

The same reactions have also used in $[17,21]$ for the determination of their correction dependencies (SI, Note 7 , Table $B$ ). The values of $\Delta_{\mathrm{r}} H^{\circ}{ }^{\circ}{ }_{298.15}(\mathrm{Y}, \mathrm{CORR})_{\mathrm{REAC}}$, determined using these correction dependencies, are also presented in Table 4.

Table 4. The homodesmotic reactions and their values of $\Delta_{\mathrm{r}} H{ }^{\circ}{ }_{298.15}(\mathrm{Y}, \mathrm{CALC})_{\mathrm{REAC}} / \Delta_{\mathrm{r}} H{ }^{\circ}{ }_{298.15}(\mathrm{Y}$, CORR $)_{\text {REAC }}$, determined for the most thermochemically favorable isomers of $\mathrm{Y}(=1 \mathrm{C}(i=1,2), 1 \mathrm{D}(i=$ 3-5), 3D $(i=6,7), 4 \mathrm{D}(i=8)$ and 6C $(i=9))$ using the different QM approaches.

\begin{tabular}{lll}
\hline$i$ & Reaction, $\left(\mathrm{R}_{\mathrm{x}}\right)_{i}$ & $\Delta_{\mathrm{r}} H_{298.15}(\mathrm{Y}, \mathrm{CALC})_{\text {REA }}$ \\
\hline & & B3LYP \\
1 & $\mathrm{C}_{6} \mathrm{H}_{4}\left(\mathrm{C}(\mathrm{O}) \mathrm{OCH}_{3}\right)_{2}+\mathrm{HC}(\mathrm{O}) \mathrm{OCH}_{2}=\mathrm{C}_{6} \mathrm{H}_{4}\left(\mathrm{C}(\mathrm{O}) \mathrm{OCH}_{3}\right) \mathrm{C}(\mathrm{O}) \mathrm{OCH}_{2}+\mathrm{HC}(\mathrm{O}) \mathrm{OCH}_{3}$ & $-3.2 /-5.4$ \\
2 & $\mathrm{C}_{6} \mathrm{H}_{4}\left(\mathrm{C}(\mathrm{O}) \mathrm{OCH}_{3}\right)_{2}+\mathrm{CH}_{3} \mathrm{C}(\mathrm{O}) \mathrm{OCH}_{2}=\mathrm{C}_{6} \mathrm{H}_{4}\left(\mathrm{C}(\mathrm{O}) \mathrm{OCH}_{3}\right) \mathrm{C}(\mathrm{O}) \mathrm{OCH}_{2}+\mathrm{CH} \mathrm{CH}_{3} \mathrm{C}(\mathrm{O}) \mathrm{OCH}_{3}$ & $-1.5 /-3.9$ \\
3 & $\mathrm{CH}_{2}\left(\mathrm{C}_{6} \mathrm{H}_{5}\right)_{2}+\mathrm{C}_{6} \mathrm{H}_{5} \mathrm{OH}+\mathrm{C}_{6} \mathrm{H}_{5} \mathrm{CH}_{2}=\mathrm{C}_{6} \mathrm{H}_{5} \mathrm{CHC} \mathrm{H}_{4} \mathrm{OH}+\mathrm{C}_{6} \mathrm{H}_{6}+\mathrm{C}_{6} \mathrm{H}_{5} \mathrm{CH}_{3}$ & $-33.6 /-32.3$ \\
4 & $\mathrm{CH}_{2}\left(\mathrm{C}_{6} \mathrm{H}_{5}\right)_{2}+\mathrm{C}_{6} \mathrm{H}_{5} \mathrm{OH}+\mathrm{CH}_{2} \mathrm{CCH}=\mathrm{C}_{6} \mathrm{H}_{5} \mathrm{CHC}_{6} \mathrm{H}_{4} \mathrm{OH}+\mathrm{C}_{6} \mathrm{H}_{6}+\mathrm{CH}_{3} \mathrm{CCH}_{2}$ & $-35.9 /-34.3$ \\
5 & $\mathrm{CH}_{2}\left(\mathrm{C}_{6} \mathrm{H}_{5}\right)_{2}+\mathrm{C}_{6} \mathrm{H}_{5} \mathrm{OH}+\mathrm{CH}_{2} \mathrm{CHCH}_{2}=\mathrm{C}_{6} \mathrm{H}_{5} \mathrm{CHC}_{6} \mathrm{H}_{4} \mathrm{OH}+\mathrm{C}_{6} \mathrm{H}_{6}+\mathrm{CH}_{3} \mathrm{CHCH}_{2}$ & $-22.6 /-17.5$ \\
6 & $\mathrm{CH}_{2}\left(\mathrm{C}_{6} \mathrm{H}_{5}\right)_{2}+\mathrm{C}_{6} \mathrm{H}_{5} \mathrm{O}=\mathrm{C}_{6} \mathrm{H}_{5} \mathrm{CH}_{2} \mathrm{C}_{6} \mathrm{H}_{4} \mathrm{O}+\mathrm{C}_{6} \mathrm{H}_{6}$ & $-5.8 /-7.7$ \\
7 & $\mathrm{CH}_{2}\left(\mathrm{C}_{6} \mathrm{H}_{5}\right)_{2}+\mathrm{CH}_{3} \mathrm{O}=\mathrm{C}_{6} \mathrm{H}_{5} \mathrm{CH}_{2} \mathrm{C}_{6} \mathrm{H}_{4} \mathrm{O}+\mathrm{CH}_{4}$ & $-120.7 /-109.2$ \\
8 & $\mathrm{CH}_{2}\left(\mathrm{C}_{6} \mathrm{H}_{5}\right)_{2}+\mathrm{C}_{6} \mathrm{H}_{5} \mathrm{OH}+\mathrm{C}_{6} \mathrm{H}_{5}=\mathrm{C}_{6} \mathrm{H}_{5} \mathrm{CH}_{2} \mathrm{C}_{6} \mathrm{H}_{3} \mathrm{OH}(4 \mathrm{Dn})+2 \mathrm{C}_{6} \mathrm{H}_{6}$ & $0.4 /-2.2$ \\
9 & $\mathrm{C}_{6} \mathrm{H}_{4}\left(\mathrm{C}(\mathrm{O}) \mathrm{OCH}_{3}\right)_{2}+\mathrm{C}_{6} \mathrm{H}_{5}=\mathrm{C}_{6} \mathrm{H}_{3}\left(\mathrm{C}(\mathrm{O}) \mathrm{OCH}_{3}\right)_{2}(6 \mathrm{C})+\mathrm{C}_{6} \mathrm{H}_{6}$ & $2.7 /-0.2$ \\
\hline
\end{tabular}

The values of $\Delta_{\mathrm{f}} H^{\circ}{ }^{\mathrm{o}}{ }_{298.15}(\mathrm{Y}, \mathrm{CORR})_{\mathrm{REAC}}$ of these structures, determined using the theoretical values of $\Delta_{\mathrm{r}} H^{{ }^{\circ}}{ }_{298.15}\left(\left(R_{\mathrm{x}}\right)_{\mathrm{i}}, \mathrm{CORR}\right)_{\mathrm{REAC}}$ and tabulated values of $\Delta_{\mathrm{f}} H^{{ }^{\circ}}{ }_{298.15}(\mathrm{X}=\mathrm{H}, \mathrm{C}$ and $\mathrm{O}, \mathrm{TAB})$, are compiled in Table 5. Their lower and upper limits are determined according to the procedure, described in [17, 21], and by the analogy with those, used above for the determination of the values of $\Delta_{\mathrm{f}} H{ }^{\circ}{ }_{298.15}(\mathrm{Y}, \mathrm{CORR})_{\mathrm{MEAN}}$ (Table 3). The uncertainty ranges for the values of $\Delta_{\mathrm{f}} H^{\circ}{ }^{\circ}{ }_{298.15}(\mathrm{Y}, \mathrm{CORR})_{\mathrm{REAC}}$, reported in Table 5, 
correspond to the values of $3 \mathrm{SE}_{\mathrm{REACi}}$, where the values of $\mathrm{SE}_{\mathrm{REACi}}$ have determined using the reported correction dependencies $[17,21]$ (SI, Note 7, Table B ). As it is mentioned above, the crossing area of these 99.7\% confidential intervals, defined for each of the considered QM approaches, has used for the determination of the lowest and upper limits of the target values. In this case, the differences between the lower and upper limits of crossing area of these confidential intervals also correspond to 6SE. The averaging of the limits of those crossing areas has used for the determination of the values of $\Delta_{\mathrm{f}} \mathrm{H}^{\mathrm{O}}{ }_{298.15}(\mathrm{Y}, \mathrm{CORR})_{\mathrm{REACMEAN}}$, also reposted in Table 5 .

Table 5. The values of $\Delta_{\mathrm{f}} H^{\mathrm{o}}{ }_{298.15}(\mathrm{Y}, \mathrm{CORR})_{\mathrm{REAC}}( \pm 3 \mathrm{SE})$, determined for the most thermochemically stable radicals using the B3LYP, M06-2X and RO/CBS-4M thermochemistry of the homodesmotic reactions, as well as the values of $\Delta_{\mathrm{f}} \mathrm{H}^{\mathrm{o}}{ }_{298.15}(\mathrm{Y}, \mathrm{CORR})_{\text {REACMEAN }}( \pm 3 \mathrm{SE})$, corresponded to the mean of their crossing area.

\begin{tabular}{|c|c|c|c|c|c|c|c|}
\hline$i$ & $\begin{array}{l}\Delta_{\mathrm{f}} H^{\mathrm{o}}{ }_{298.15}(\mathrm{Y}, \\
\mathrm{CORR})_{\text {REAC }} \\
\mathrm{kJ} / \mathrm{mol}\end{array}$ & $\begin{array}{l}\Delta_{\mathrm{f}} H^{\mathrm{o}} 298.15(\mathrm{Y}, \\
\mathrm{CORR})_{\mathrm{REAC}} \\
\mathrm{kJ} / \mathrm{mol}\end{array}$ & $\begin{array}{l}\Delta_{\mathrm{f}} H^{\mathrm{o}}{ }_{298.15}(\mathrm{Y} \\
\mathrm{CORR})_{\mathrm{REAC}} \\
\mathrm{kJ} / \mathrm{mol}\end{array}$ & $\begin{array}{l}\Delta_{\mathrm{f}} H^{\mathrm{o}}{ }_{298.15}(\mathrm{Y}, \\
\mathrm{CORR})_{\mathrm{REAC}} \\
\mathrm{kJ} / \mathrm{mol}\end{array}$ & $\begin{array}{l}\Delta_{\mathrm{f}} H^{\mathrm{o}} 298.15(\mathrm{Y} \\
\mathrm{CORR})_{\mathrm{REAC}} \\
\mathrm{kJ} / \mathrm{mol}\end{array}$ & $\begin{array}{l}\Delta_{\mathrm{f}} H^{\mathrm{o}}{ }_{298.15}(\mathrm{Y} \\
\mathrm{CORR})_{\mathrm{REAC}} \\
\mathrm{kJ} / \mathrm{mol}\end{array}$ & $\begin{array}{l}\Delta_{\mathrm{f}} H^{\mathrm{o}}{ }_{298.15}(\mathrm{Y} \\
\mathrm{CORR})_{\mathrm{REACN}} \\
\mathrm{kJ} / \mathrm{mol}\end{array}$ \\
\hline & $\begin{array}{l}\text { B3LYP } \\
( \pm 19)\end{array}$ & $\begin{array}{l}\text { M06-2X } \\
( \pm 10.2)\end{array}$ & $\begin{array}{l}\text { CBS-4M } \\
( \pm 16.5)\end{array}$ & $\begin{array}{l}\text { ROCBS-4M } \\
( \pm 15.6)\end{array}$ & Lower & Upper & \\
\hline $1 \mathrm{C}$ & $1 \mathrm{C}$ & $1 \mathrm{C}$ & $1 \mathrm{C}$ & $1 \mathrm{C}$ & $1 \mathrm{C}$ & $1 \mathrm{C}$ & $1 \mathrm{C}$ \\
\hline 1 & -410 & -410.7 & -394.4 & -408.6 & -400.5 & -410.9 & $-405.7 \pm 5$ \\
\hline 2 & -421.6 & -421.9 & -405.4 & -419.2 & -411.7 & -421.9 & $-416.9 \pm 5$ \\
\hline 1D & 1D & 1D & 1D & 1D & 1D & 1D & 1D \\
\hline 3 & 114.5 & 116.9 & 121.0 & 99.5 & 106.7 & 115.1 & $116.4 \pm 10$ \\
\hline 4 & 117.2 & 116.4 & 130.8 & 99.6 & 114.3 & 115.2 & $120.5 \pm 6$ \\
\hline \multirow[t]{2}{*}{5} & 115.4 & 115.4 & 124.1 & 106.0 & 107.6 & 122.5 & $115.4 \pm 10$ \\
\hline & & & & & 114.3 & 115.1 & $114.7 \pm 0.4$ \\
\hline $3 \mathrm{D}$ & $3 \mathrm{D}$ & $3 \mathrm{D}$ & $3 \mathrm{D}$ & $3 \mathrm{D}$ & 3D & 3D & 3D \\
\hline 6 & 130.3 & 130.8 & 134.7 & 130.9 & 120.6 & 141.0 & $130.8 \pm 10$ \\
\hline \multirow[t]{2}{*}{7} & 152.1 & 140.7 & 136.0 & 135.0 & 130.5 & 150.9 & $140.7 \pm 10$ \\
\hline & & & & & 130.5 & 141.0 & $135.8 \pm 5$ \\
\hline $4 \mathrm{D}$ & $4 \mathrm{D}$ & $4 \mathrm{D}$ & $4 \mathrm{D}$ & $4 \mathrm{D}$ & $4 \mathrm{D}$ & $4 \mathrm{D}$ & $4 \mathrm{D}$ \\
\hline 8 & 237.2 & 241.4 & 236.6 & 239.7 & 231.2 & 241.6 & $241.4 \pm 10$ \\
\hline $5 \mathrm{C}$ & $5 \mathrm{C}$ & $5 \mathrm{C}$ & $5 \mathrm{C}$ & $5 \mathrm{C}$ & $5 \mathrm{C}$ & $5 \mathrm{C}$ & $5 \mathrm{C}$ \\
\hline 9 & -352.4 & -352.0 & -349.6 & -351.8 & -341.8 & -362.2 & $-352.0 \pm 10$ \\
\hline
\end{tabular}

As can be seen from Table 5 , the value of $\Delta_{\mathrm{f}} H^{\circ}{ }_{298.15}(\mathrm{Y}, \mathrm{CORR})_{\text {REACMEAN }}$, calculated using the thermochemistry of reaction 2, is significantly lower (outside of the 3SE uncertainties ranges), than those values, determined using the thermochemistry of atomization reactions (Table 3) and homodesmotic reaction 1 (Table 5). This discrepancy can be attributed to the uncertainty, reported for the value of $\Delta_{\mathrm{f}} H$ ${ }^{\circ}{ }_{298.15}\left(\mathrm{CH}_{2} \mathrm{OC}(\mathrm{O}) \mathrm{CH}_{3}\right)(=-221.6 \pm 8 \mathrm{~kJ} / \mathrm{mol})$ in [37]. Thus, the values of $\Delta_{\mathrm{f}} \mathrm{H}^{\mathrm{o}}{ }_{298.15}\left(\mathrm{CH}_{2} \mathrm{OC}(\mathrm{O}) \mathrm{CH}_{3}\right)_{\text {atom }}$, calculated in the present work using the different QM approaches (Table 6, 1F), are consistent one with others as well as are systematically $(6-23 \mathrm{~kJ} / \mathrm{mol})$ higher than its tabulated value. However, both the tabulated $\left(\Delta_{\mathrm{f}} \mathrm{H}^{\circ}{ }_{298.15}\left(\mathrm{CH}_{2} \mathrm{OC}(\mathrm{O}) \mathrm{CH}_{3}\right)\right)$ and the calculated $\left(\Delta_{\mathrm{f}} \mathrm{H}^{\circ}{ }_{298.15}\left(\mathrm{CH}_{2} \mathrm{OC}(\mathrm{O}) \mathrm{CH}_{3}\right)_{\text {MEAN }}\right)$ values are lying within their uncertainties ranges.

Table 6. The values of $\Delta_{\mathrm{f}} \mathrm{H}^{\mathrm{o}}{ }_{298.15}\left(\mathrm{CH}_{2} \mathrm{OC}(\mathrm{O}) \mathrm{CH}_{3}, \mathrm{CORR}\right)_{\text {atom }}( \pm 3 \mathrm{SE})$, determined using the different QM approaches, as well as their mean values of $\Delta_{\mathrm{f}} \mathrm{H}^{{ }^{\circ}}{ }_{298.15}\left(\mathrm{CH}_{2} \mathrm{OC}(\mathrm{O}) \mathrm{CH}_{3}, \mathrm{CORR}\right)_{\text {MEAN }}( \pm 3 \mathrm{SE})$, determined using the upper and lower limits $(6 \mathrm{SE})$ of the common area of the uncertainty ranges of the values of $\Delta_{\mathrm{f}} H$ ${ }_{298.15}\left(\mathrm{CH}_{2} \mathrm{OC}(\mathrm{O}) \mathrm{CH}_{3}, \mathrm{CORR}\right)_{\text {atom }}$. (The values of errors correspond to $3 \mathrm{SE}$, determined for the correction dependencies reported in [21] (SI, Note 7$)$ ). 


\begin{tabular}{|c|c|c|c|c|c|c|c|}
\hline & $\begin{array}{l}\Delta_{\mathrm{f}} H^{\mathrm{o}}{ }_{298.15}\left(\mathrm{Y}^{\prime}\right. \\
\mathrm{CORR})_{\text {atom }} \\
\mathrm{kJ} / \mathrm{mol}\end{array}$ & $\begin{array}{l}\Delta_{\mathrm{f}} H^{\mathrm{o}}{ }_{298.15}\left(\mathrm{Y}^{\prime}\right. \\
\mathrm{CORR})_{\text {atom }} \\
\mathrm{kJ} / \mathrm{mol}\end{array}$ & $\begin{array}{l}\Delta_{\mathrm{f}} H^{\mathrm{o}}{ }_{298.15}\left(\mathrm{Y}^{\prime}\right. \\
\mathrm{CORR})_{\text {atom }} \\
\mathrm{kJ} / \mathrm{mol}\end{array}$ & $\begin{array}{l}\Delta_{\mathrm{f}} H^{\mathrm{o}}{ }_{298.15}\left(\mathrm{Y}^{\prime}\right. \\
\mathrm{CORR})_{\text {atom }} \\
\mathrm{kJ} / \mathrm{mol}\end{array}$ & $\begin{array}{l}\Delta_{\mathrm{f}} H^{\mathrm{o}}{ }_{298.15}(\mathrm{Y} \\
\mathrm{CORR})_{\text {atom }} \\
\mathrm{kJ} / \mathrm{mol}\end{array}$ & $\begin{array}{l}\Delta_{\mathrm{f}} H^{\mathrm{o}}{ }_{298.15}(\mathrm{Y} \\
\mathrm{CORR})_{\text {atom }} \\
\mathrm{kJ} / \mathrm{mol}\end{array}$ & $\begin{array}{l}\Delta_{\mathrm{f}} H^{\mathrm{o}}{ }_{298.15}\left(\mathrm{Y}^{\prime}\right. \\
\mathrm{CORR})_{\text {MEAN }}, \\
\mathrm{kJ} / \mathrm{mol}\end{array}$ \\
\hline & $\begin{array}{l}\text { B3LYP } \\
( \pm 33.6)\end{array}$ & $\begin{array}{l}\text { M06-2X } \\
( \pm 11.4)\end{array}$ & $\begin{array}{l}\text { CBS-4M } \\
( \pm 25.2)\end{array}$ & $\begin{array}{l}\text { ROCBS- } \\
4 \mathrm{M} \\
( \pm 27.6)\end{array}$ & Lower & Upper & \\
\hline $1 \mathrm{~F}$ & -215.2 & -215.2 & -198.6 & -200.5 & -223.8 & -203.8 & $-213 \pm 10$ \\
\hline $2 \mathrm{~F}$ & -157.1 & -161.8 & -146.3 & -149.0 & -171.5 & -150.4 & $-161 \pm 11$ \\
\hline
\end{tabular}

On the contrary, the values of $\Delta_{\mathrm{f}} \mathrm{H}^{\mathrm{o}}{ }_{298.15}\left(\mathrm{CH}_{2} \mathrm{OC}(\mathrm{O}) \mathrm{CH} \text {, CORR }\right)_{\text {atom }}$, calculated using the same QM approaches (Table $6,2 \mathrm{~F}$ ), are not systematically lower or higher its tabulated value $(=-156.9 \pm 1.7 \mathrm{~kJ} / \mathrm{mol}, S I$, Note 1 ) and are rather demonstrating their dispersion around it. As a result, the value of $\Delta_{\mathrm{f}} H^{\circ}{ }_{298.15}(\mathrm{Y}$, CORR) REACMEAN , determined using the thermochemistry of the homodesmotic reaction $i=1$ (Table 5), is considered as the more reliable than hose value, derived on the basis of reaction $i=2$ (Table 5 ). This conclusion agrees with the value of $\Delta_{\mathrm{f}} H^{\circ}{ }_{298.15}(\mathrm{Y}, \mathrm{CORR})_{\text {MEAN }}$, determined using the corrected thermochemistry of atomization reactions.

The most accurate and consistent values of $\Delta_{\mathrm{f}} H{ }^{\mathrm{o}}{ }_{298.15}(\mathrm{Y}, \mathrm{CORR}$ ) REACMEAN (marked bold in Tables 3 and 5) that agree with the other theoretical values, determined in the present study, are considered as the most reliable. Most of these values are determined using thermochemistry homodesmotic reactions $\left(\Delta_{\mathrm{f}} H\right.$ ${ }^{\circ}{ }_{298.15}(\mathrm{Y}, \mathrm{CORR})_{\text {REACMEAN }}$ ), Table 5). However, in the case of structures $1 \mathrm{C}$ and $5 \mathrm{C}$, the uncertainties ranges for their values of $\Delta_{\mathrm{f}} \mathrm{H}^{\mathrm{o}}{ }_{298.15}(\mathrm{Y}, \mathrm{CORR})_{\mathrm{MEAN}}$, calculated using the thermochemistry of atomization reactions, are recommended due to their smaller $99.7 \%$ confidence intervals than those, determined using the thermochemistry of homodesmotic reactions (Table $5, i=1,9$ ).

The values of $\Delta_{\mathrm{f}} \mathrm{H}^{\mathrm{o}}{ }_{298.15}(\mathrm{Y}, \mathrm{CORR})_{\mathrm{REACMEAN}}$ of others isomers, can also be determined using the thermochemistry of their homodesmotic tautomerization reactions and the values of $\Delta_{\mathrm{f}} H{ }^{\circ}{ }_{298.15}(\mathrm{Y}$, CORR) REACMEAN, reported in the present work for the structures $1 \mathrm{C}, 5 \mathrm{C}, 1 \mathrm{D}, 3 \mathrm{D}$ and $4 \mathrm{D}$.

Noticeably, in the case of structures $8 \mathrm{D}$ and $9 \mathrm{D}$, the rotation of $\mathrm{OH}$ group leads to formation of the 6-10 $\mathrm{kJ} / \mathrm{mol}$ less thermochemically stable conformers (respectively, 19D and 20D). This result is probably due to the interaction of unpaired electron with $\mathrm{H}$ atom of hydroxyl group. As a result, the lower values of entropy of the structures 8D and 9D, compared those for the structures 19D and 20D, are expected.

\subsubsection{Determination of the values of $S^{o} 298.15(Y)$}

The values of $S{ }^{\circ}{ }_{298.15}$ (Y, CALC), determined in the present study using the values of $H^{\circ}{ }_{298.15}(\mathrm{Y}, \mathrm{CALC})$ and $G{ }^{\circ}{ }_{298.15}$ (Y, CALC), are presented in Table 7. As can be seen, these values are mainly consistent and do not depend upon used QM approach. The effect of the restricted open shell wavefunction is not observed and is not expected $[17,21]$. Therefore, the only results of B3LYP, M06-2X and CBS-4M calculations of $S$ ${ }_{298.15}(\mathrm{Y}, \mathrm{CALC})$ are reported.

As can be seen the highest difference between the values of $S^{\circ}{ }_{298.15}(\mathrm{Y}, \mathrm{CALC})$ of conformers and tautomers, determined within the same QM approach, is too small for affecting the qualitative distribution between the considered isomers of radicals, formed by abstraction of $\mathrm{H}$ atom from $1,2-\mathrm{C}_{6} \mathrm{H}_{4}\left(\mathrm{CO}_{2} \mathrm{CH}_{3}\right)_{2}(<15 \mathrm{~J} /(\mathrm{mol}$ $\mathrm{K})$ ) and $\mathrm{p}-\mathrm{C}_{6} \mathrm{H}_{5} \mathrm{CH}_{2} \mathrm{C}_{6} \mathrm{H}_{4} \mathrm{OH}(<30 \mathrm{~J} /(\mathrm{mol} \mathrm{K}))$ at room or elevated temperatures. Thus, the B3LYP values of $\Delta_{\mathrm{r}} S{ }^{\circ}{ }_{298.15}(1 \mathrm{C}-11 \mathrm{C}) \times T=31.2 \mathrm{~kJ} / \mathrm{mol}$ and $\Delta_{\mathrm{r}} S{ }^{\circ}{ }_{298.15}(1 \mathrm{D}-13 \mathrm{D}) \times T=59.4 \mathrm{~kJ} / \mathrm{mol}$ at $T=2000 \mathrm{~K}$ are significantly smaller than the standard enthalpies of these reaction, which correspond, respectively, to 60 70 and $140 \mathrm{~kJ} / \mathrm{mol}$ (Table 3). The even smaller values of $\Delta_{\mathrm{r}} S{ }^{\circ}{ }_{298.15}(1 \mathrm{C}-11 \mathrm{C}) \times T=7.4 \mathrm{~J} /(\mathrm{mol} \mathrm{K}$ ) and $\Delta_{\mathrm{r}} S^{\circ}{ }_{298.15}(1 \mathrm{D}-13 \mathrm{D}) \times T=37.6 \mathrm{~J} /(\mathrm{mol} K)$ for these reactions $(T=2000 \mathrm{~K})$ are predicted by the CBS-4M calculations. The observed differences between the values of $\Delta_{\mathrm{r}} S{ }^{{ }^{\circ}}{ }_{298.15}(1 \mathrm{C}-11 \mathrm{C})$ or $\Delta_{\mathrm{r}} S{ }^{\mathrm{o}}{ }_{298.15}(1 \mathrm{D}-13 \mathrm{D})$, determined in the present work using the different QM approaches, is most probably due to the accuracy of calculations of the vibration frequencies. As a result, the different QM approaches predict the highest 
values of $\Delta_{\mathrm{r}} S{ }^{\circ}{ }_{298.15}$ of isomerization of the $1 \mathrm{C}$ and $1 \mathrm{D}$ for the different structures. Thus, the B3LYP and M06-2X approaches suggests its highest values for the reaction (1C-11C), while, the CBS-4M calculation for the reaction $(1 \mathrm{C}-6 \mathrm{C})\left(\Delta_{\mathrm{r}} S{ }^{\circ}{ }_{298.15}(1 \mathrm{C}-6 \mathrm{C}) \times T=23.4 \mathrm{~kJ} / \mathrm{mol}\right)$. The same discrepancy, but for all three considered QM approaches, is observed for the reaction of tautomerization of 1D. Thus, the highest values of $\Delta_{\mathrm{r}} S{ }^{\circ}{ }_{298.15}(1 \mathrm{D}-4 \mathrm{D}) \times T=60.6 \mathrm{~kJ} / \mathrm{mol}$ and $\Delta_{\mathrm{r}} S{ }^{\mathrm{o}_{298.15}}(1 \mathrm{D}-17 \mathrm{D}) \times T=47.2 \mathrm{~kJ} / \mathrm{mol}($ at $T=2000 \mathrm{~K})$ are determined, respectively, using the M06-2X and CBS-4M approaches. However, these observations don't affecting the qualitative distribution between the main tautomers of these radicals.

The corrections of these values of $S^{\circ}{ }_{298.15}(\mathrm{Y}, \mathrm{CALC})$ using the reported dependencies [17, 21] don't affecting significantly these differences as well. The corrected values of $S{ }^{\circ}{ }_{298.15}(\mathrm{Y}, \mathrm{CORR})$ are presented in Table 7. The uncertainties, reported for these values in Table 7 (in parentheses), correspond to the values of 2SE, determined previously for the B3LYP $\left(-4.47+1.015 \times S^{\circ}{ }_{298.15}\right.$ (X, B3LYP), [21]), CBS-4M $(-10.35+1.037 \times S$ $\left.{ }_{298.15}(\mathrm{X}, \mathrm{RO} / \mathrm{CBS}-4 \mathrm{M})[17]\right)$ and M06-2X $\left(-21.13+1.0587 \times S^{\circ}{ }_{298.15}(\mathrm{X}, \mathrm{M} 06-2 \mathrm{X})\right.$ [21]) correction dependencies.

Table 7. The values of $S^{\circ}{ }_{298.15}$ (Y, CALC) of considered radicals (1C-12C, 1D-21D), as well as their corrected values of $S^{\circ}{ }_{298.15}(\mathrm{Y}, \mathrm{CORR})$, calculated using the different $\mathrm{QM}$ approaches $( \pm 2 \mathrm{SE})$.

\begin{tabular}{|c|c|c|c|c|c|c|}
\hline Y & $\begin{array}{l}S^{\mathrm{o}}{ }_{298.15}(\mathrm{Y}, \\
\mathrm{CALC}) \\
\mathrm{J} /(\mathrm{mol} \mathrm{K})\end{array}$ & $\begin{array}{l}S^{\mathrm{o}}{ }_{298.15}(\mathrm{Y}, \\
\mathrm{CALC}) \\
\mathrm{J} /(\mathrm{mol} \mathrm{K})\end{array}$ & $\begin{array}{l}S^{\mathrm{o}}{ }_{298.15}(\mathrm{Y}, \\
\mathrm{CALC}), \\
\mathrm{J} /(\mathrm{mol} \mathrm{K})\end{array}$ & $\begin{array}{l}S^{\mathrm{o}}{ }_{298.15}(\mathrm{Y}, \\
\mathrm{CORR}) \\
\mathrm{J} /(\mathrm{mol} \mathrm{K})\end{array}$ & $\begin{array}{l}S^{\mathrm{o}}{ }_{298.15}(\mathrm{Y}, \\
\mathrm{CORR}) \\
\mathrm{J} /(\mathrm{mol} \mathrm{K})\end{array}$ & $\begin{array}{l}S^{\mathrm{o}}{ }_{298.15}(\mathrm{Y}, \\
\mathrm{CORR}), \\
\mathrm{J} /(\mathrm{mol} \mathrm{K})\end{array}$ \\
\hline & B3LYP & M06-2X & CBS-4M & $\begin{array}{l}\text { B3LYP } \\
( \pm 17.6)\end{array}$ & M06-2X $( \pm 20)$ & $\begin{array}{l}\text { CBS-4M } \\
( \pm 15.6)\end{array}$ \\
\hline $1 \mathrm{C}$ & 493.1 & 484.9 & 497.4 & 496.0 & 492.2 & 505.5 \\
\hline $2 \mathrm{C}$ & $\mathrm{N} / \mathrm{A}$ & 490.1 & 493.7 & $\mathrm{~N} / \mathrm{A}$ & 497.7 & 501.6 \\
\hline $3 \mathrm{C}$ & 499.0 & 489.1 & 502.4 & 502.0 & 496.7 & 510.6 \\
\hline $4 \mathrm{C}$ & 496.2 & 487.6 & 497.1 & 499.2 & 495.1 & 505.2 \\
\hline $5 \mathrm{C}$ & 496.3 & 489.2 & 501.5 & 499.3 & 496.8 & 509.7 \\
\hline $6 \mathrm{C}$ & 500.1 & 491.5 & 509.1 & 503.1 & 499.2 & 517.6 \\
\hline $7 \mathrm{C}$ & 501.7 & 492.9 & 504.1 & 504.8 & 500.7 & 512.4 \\
\hline $8 \mathrm{C}$ & 497.5 & 488.2 & 503.9 & 500.5 & 495.7 & 512.2 \\
\hline $9 \mathrm{C}$ & 497.2 & 488.1 & 504.7 & 500.2 & 495.6 & 513.0 \\
\hline $10 \mathrm{C}$ & 508.3 & 489.1 & 504.3 & 511.5 & 496.7 & 512.6 \\
\hline $11 \mathrm{C}$ & 508.7 & 495.0 & 501.1 & 511.9 & 502.9 & 509.3 \\
\hline $12 \mathrm{C}$ & 497.5 & 492.7 & 498.5 & 500.5 & 500.5 & 506.6 \\
\hline 1D & 448.0 & 447.2 & 454.1 & 450.3 & 452.3 & 460.6 \\
\hline $2 \mathrm{D}$ & 448.7 & 447.1 & 454.1 & 451.0 & 452.2 & 460.6 \\
\hline $3 \mathrm{D}$ & 466.0 & 466.0 & 461.2 & 468.5 & 472.2 & 467.9 \\
\hline $4 \mathrm{D}$ & 470.3 & 477.5 & 466.3 & 472.9 & 484.4 & 473.2 \\
\hline $5 \mathrm{D}$ & 470.1 & 466.7 & 465.5 & 472.7 & 473.0 & 472.4 \\
\hline $6 \mathrm{D}$ & 474.2 & 468.7 & 473.1 & 476.8 & 475.1 & 480.3 \\
\hline 7D & 474.9 & 469.8 & 472.3 & 477.6 & 476.2 & 479.4 \\
\hline $8 \mathrm{D}$ & 470.6 & 471.5 & 471.4 & 473.2 & 478.0 & 478.5 \\
\hline 9D & 471.1 & 467.4 & 470.9 & 473.7 & 473.7 & 478.0 \\
\hline 10D & 470.5 & 469.0 & 470.5 & 473.1 & 475.4 & 477.6 \\
\hline 11D & 471.0 & 468.4 & 469.1 & 473.6 & 474.8 & 476.1 \\
\hline $12 \mathrm{D}$ & 470.7 & 467.2 & 470.4 & 473.3 & 473.5 & 477.5 \\
\hline $13 \mathrm{D}$ & 477.7 & 467.8 & 472.9 & 480.4 & 474.1 & 480.1 \\
\hline $14 \mathrm{D}$ & 474.1 & 467.4 & 473.4 & 476.7 & 473.7 & 480.6 \\
\hline $15 \mathrm{D}$ & 471.0 & 474.0 & 473.3 & 473.6 & 480.7 & 480.5 \\
\hline 16D & 476.6 & 474.3 & 474.5 & 479.3 & 481.0 & 481.7 \\
\hline 17D & 474.1 & 473.1 & 477.7 & 476.7 & 479.7 & 485.0 \\
\hline
\end{tabular}




\begin{tabular}{lllllll}
\hline & $S^{\mathrm{o}}{ }_{298.15}(\mathrm{Y}$, & $S^{\circ}{ }_{298.15}(\mathrm{Y}$, & $S^{\mathrm{o}}{ }_{298.15}(\mathrm{Y}$, & $S^{\mathrm{o}}{ }_{298.15}(\mathrm{Y}$, & $S^{\circ}{ }_{298.15}(\mathrm{Y}$, & $S^{\mathrm{o}}{ }_{298.15}(\mathrm{Y}$, \\
& $\mathrm{CALC})$, & $\mathrm{CALC})$, & $\mathrm{CALC})$, & $\mathrm{CORR})$, & $\mathrm{CORR})$, & $\mathrm{CORR})$, \\
$\mathrm{Y}$ & $\mathrm{J} /(\mathrm{mol} \mathrm{K})$ & $\mathrm{J} /(\mathrm{mol} \mathrm{K})$ & $\mathrm{J} /(\mathrm{mol} \mathrm{K})$ & $\mathrm{J} /(\mathrm{mol} \mathrm{K})$ & $\mathrm{J} /(\mathrm{mol} \mathrm{K})$ & $\mathrm{J} /(\mathrm{mol} \mathrm{K})$ \\
\hline $18 \mathrm{D}$ & 470.0 & 469.2 & 470.2 & 472.6 & 475.6 & 477.3 \\
$19 \mathrm{D}$ & 469.5 & 469.2 & 472.0 & 472.1 & 475.6 & 479.1 \\
$20 \mathrm{D}$ & 467.9 & 469.6 & 472.2 & 470.5 & 476.0 & 479.3 \\
$21 \mathrm{D}$ & 477.2 & 469.5 & 473.3 & 479.9 & 475.9 & 480.5 \\
\hline
\end{tabular}

As can be seen, the CBS- $4 \mathrm{M}$ values of $S{ }^{\mathrm{o}}{ }_{298.15}(1 \mathrm{C}, \mathrm{CORR})$ and $S{ }^{\mathrm{o}}{ }_{298.15}(1 \mathrm{D}, \mathrm{CORR})$, determined in the present study, are 5-6 kJ/mol higher and lower those values estimated, respectively, for Dimethyl phthalate $(500.9 \pm 15.6( \pm 2 \mathrm{SE}) \mathrm{J} /(\mathrm{mol} K)[21])$ and p-Benzylphenol $(465.0 \pm 15.6( \pm 2 \mathrm{SE}) \mathrm{J} /(\mathrm{mol} \mathrm{K})[21])$. At the same time, the difference between their B3LYP values is close to $1 \mathrm{~J} /(\mathrm{mol} K)$ in the case of Dimethyl phthalate $(494.6 \pm 17.6( \pm 2 \mathrm{SE}) \mathrm{J} /(\mathrm{mol} K)[21])$, and is near $12 \mathrm{~J} /(\mathrm{mol} K)$ for the p-Benzylphenol $(462.6 \pm 17.6 \mathrm{~J} /(\mathrm{mol}$ $K$ ) [21]). In the case of M06-2X calculations, the difference near $1 \mathrm{~kJ} / \mathrm{mol}$, similar those determined using the B3LYP approach, is only observed for the Dimethyl phthalate $(491.3 \mathrm{~J} /(\mathrm{mol} K)$ [21]), while, for the p-Benzylphenol, the difference $(=19 \mathrm{~kJ} / \mathrm{mol})$ between the value of $S^{\circ}{ }_{298.15}(1 \mathrm{~B}, \mathrm{CORR})$ [21] and the value of $S^{\circ}{ }_{298.15}(1 \mathrm{D}, \mathrm{CORR})$, determined in the present work, is higher those derived from CBS-4M and B3LYP calculations.

At the same time, the consistent differences between the values of $S{ }^{\circ}{ }_{298.15}$ (p-Benzylphenol) [21] and $S$ ${ }^{\circ}{ }_{298.15}$ (3D, CORR) are calculated using all considered approaches. Thus, the CBS-4M value of this difference $(2.9 \mathrm{~J} /(\mathrm{mol} \mathrm{K}))$ is slightly higher and lower, respectively, those values, determined using the M06-2X $(0.8$ $\mathrm{J} /(\operatorname{mol} K))$ and B3LYP $(4.9 \mathrm{~J} /(\mathrm{mol} K))$ approaches. These values are not far away from the difference of $-3 \mathrm{~J} /(\mathrm{mol} K)$, determined using the tabulated values of phenol and phenoxy radical $\left(S^{\circ}{ }_{298.15}\left(\mathrm{C}_{6} \mathrm{H}_{5} \mathrm{OH}\right.\right.$, $\mathrm{TAB})(=315 \mathrm{~J} /(\mathrm{mol} K))$ and $S{ }^{\circ}{ }_{298.15}\left(\mathrm{C}_{6} \mathrm{H}_{5} \mathrm{O}\right.$, TAB $)(=312 \mathrm{~J} /(\mathrm{mol} K))$ [37]). The same result is also observed for the tabulated values of $S^{\circ}{ }_{298.15}\left(\mathrm{C}_{6} \mathrm{H}_{5} \mathrm{CH}_{3}\right.$, TAB) $(=320 \mathrm{~J} /(\mathrm{mol} \mathrm{K}))$ and $S^{\circ}{ }_{298.15}\left(\mathrm{C}_{6} \mathrm{H}_{5} \mathrm{CH}_{2}\right.$, $\mathrm{TAB})\left(=318 \mathrm{~J} /(\mathrm{mol} K)\right.$, or $S^{\circ}{ }_{298.15}\left(\mathrm{CH}_{3} \mathrm{OH}, \mathrm{TAB}\right)(=239 \mathrm{~J} /(\mathrm{mol} \mathrm{K}))$ and $S^{\circ}{ }_{298.15}\left(\mathrm{CH}_{3} \mathrm{O}, \mathrm{TAB}\right)(=234$ $\mathrm{J} /(\operatorname{mol} K))[37]$. The observed slight discrepancy between these and calculated values can be explained by the uncertainties of calculations. From this point of view, the CBS-4M values of $S^{\circ}{ }_{298.15}$ (p-Benzylphenol) [21] and $S{ }^{\circ}{ }_{298.15}$ (1D, CORR) have the smallest uncertainty range and are considered as the most reliable. Thus, generally speaking, the removing of one atom from compound should decrease the entropy, due to the lost of mass, lost of one (or more) vibration component, as well as due to the slightly smaller size of radical. However, in some cases, such logical line does not work and some correction of these values can also be expected.

For example, the removing of $\mathrm{H}$ atom from Benzaldehyde $(336 \mathrm{~J} /(\mathrm{mol} \mathrm{K}))$ leads to the formation of $\mathrm{C}_{6} \mathrm{H}_{5} \mathrm{CO}$, for which the tabulated value of $S^{\circ}{ }_{298.15}\left(\mathrm{C}_{6} \mathrm{H}_{5} \mathrm{CO}\right.$, TAB $)=342 \mathrm{~J} /(\mathrm{mol} \mathrm{K})[37]$ is $6 \mathrm{~J} /(\mathrm{mol} \mathrm{K})$ higher. The same effect can also be demonstrated for the pairs of $\mathrm{CH}_{3}\left(S^{\circ}{ }_{298.15}\left(\mathrm{CH}_{3}\right.\right.$, TAB $\left.)=194 \mathrm{~J} /(\mathrm{mol} \mathrm{K})\right)$ and $\mathrm{CH}_{4}\left(S^{\circ}{ }_{298.15}\left(\mathrm{CH}_{4}, \mathrm{TAB}\right)=186 \mathrm{~J} /(\mathrm{mol} \mathrm{K})\right)$, or $\mathrm{CH}_{2} \mathrm{OH}\left(S^{\mathrm{o}}{ }_{298.15}\left(\mathrm{CH}_{2} \mathrm{OH}, \mathrm{TAB}\right)=244 \mathrm{~J} /(\mathrm{mol} \mathrm{K})\right)$ and $\mathrm{CH}_{3} \mathrm{OH}\left(S^{\circ}{ }_{298.15}\left(\mathrm{CH}_{3} \mathrm{OH}, \mathrm{TAB}\right)=239 \mathrm{~J} /(\mathrm{mol} \mathrm{K})\right)[37]$. These observations are, most probably, due to the effect of $\mathrm{H}$ atom abstraction on the symmetry and the vibration frequencies of atoms in the formed radicals, and cannot be attributed to the internal rotations, which are not considered in this study for the entropies calculations [36], but corrected using the correction dependencies. Thus, the $\mathrm{C}_{6} \mathrm{H}_{5}$ and $\mathrm{C}_{6} \mathrm{H}_{6}$ do not have the internal rotations, but the value of $S^{\circ}{ }_{298.15}\left(\mathrm{C}_{6} \mathrm{H}_{5}\right.$, TAB $)(=286.1 \mathrm{~J} /(\mathrm{mol} \mathrm{K}))$ is $17 \mathrm{~J} /(\mathrm{mol} \mathrm{K})$ higher than the value of $S^{\circ}{ }_{298.15}\left(\mathrm{C}_{6} \mathrm{H}_{6}, \mathrm{TAB}\right)(=269.2 \mathrm{~J} /(\mathrm{mol} \mathrm{K}))[37]$.

The last pair of values is slightly better consistent with the results of B3LYP and M06-2X calculations than with results, determined using the CBS-4M approach. Thus, the differences between the values of $S{ }^{\circ}{ }_{298.15}$ (pBenzylphenol $)_{\mathrm{CBS}-4 \mathrm{M}}(=465.0 \pm 15.6 \mathrm{~J} /(\mathrm{mol} \mathrm{K}))$ and $S{ }^{{ }^{\circ}}{ }_{298.15}(4 \mathrm{D}, \mathrm{CORR})_{\mathrm{CBS}-4 \mathrm{M}}$ corresponds to $8.2 \mathrm{~J} /(\mathrm{mol}$ $\mathrm{K})$, while, the differences between those values, determined using the B3LYP and M06-2X approaches, are, respectively, 10.3 and $13 \mathrm{~J} /(\mathrm{mol} \mathrm{K})$. However, all these values are lying within reported uncertainties and cannot be used as the argument for preference of one of the determined values. 
The same conclusion can be made for the values of $S^{\circ}{ }_{298.15}$, calculated using the CBS-4M approach for the radicals, formed by the abstraction of $\mathrm{H}$ atom from Dimethyl phthalate. Thus, the difference of 5-6 J/(mol $\mathrm{K}$ ) between the values of $S^{\circ}{ }_{298.15}$ (Dimethyl phthalate) ${ }_{\mathrm{CBS}-4 \mathrm{M}}$ and $S^{\circ}{ }_{298.15}(1 \mathrm{C}, \mathrm{CORR})_{\mathrm{CBS}-4 \mathrm{M}}$ is closer those values, determined for pairs $\mathrm{CH}_{4} / \mathrm{CH}_{3}$ or $\mathrm{CH}_{3} \mathrm{OH} / \mathrm{CH}_{2} \mathrm{OH}$, than that value determined using the B3LYP approach. However, the difference of $16-18 \mathrm{~J} /(\mathrm{mol} \mathrm{K})$ between the values of $S{ }^{\circ}{ }_{298.15}$ (Dimethyl phthalate) [21] and $S{ }^{\circ}{ }_{298.15}(\mathrm{Y}, \mathrm{CORR})$, calculated using the CBS-4M $(\mathrm{Y}=6 \mathrm{C})$, as well as the B3LYP $(\mathrm{Y}=11 \mathrm{C})$ approaches, are both consistent with the tabulated values of $S{ }^{\circ}{ }_{298.15}\left(\mathrm{C}_{6} \mathrm{H}_{5}, \mathrm{TAB}\right)$ and $S^{\circ}{ }_{298.15}\left(\mathrm{C}_{6} \mathrm{H}_{6}, \mathrm{TAB}\right)$.

As a result, it can be concluded, that all values of entropy of considered radicals can be used within recommended uncertainties. However, CBS-4M values, as well as the corrected (using considered correction dependencies) B3LYP and M06-2X values, cannot be used for the determination of the vibration frequencies of compounds, their temperature dependencies and IR spectra. Therefore, the not corrected results of B3LYP calculations are used for these purposes instead.

\subsubsection{IR spectra of the most thermochemically stable radicals.}

The IR spectra of the most thermochemically favorable isomers of these radicals, determined using B3LYP/6$311++\mathrm{G}(\mathrm{d}, \mathrm{p})$, are presented in Figures $3 \mathrm{a}$ and $3 \mathrm{~b}$, respectively, for the structures $1 \mathrm{C}$ and $1 \mathrm{D} / 3 \mathrm{D}$. The values of wavenumber, used for these spectra, correspond to their original vibration frequencies, not corrected using the recommended scaling factor. Unfortunately, the spectra of these radicals are not measured or not reported in the literature. Therefore, the spectra of Dimethyl phthalate and p-Benzylphenol are used for the comparison with the calculated IR spectra of most thermochemically stable radicals instead.

Figure 3. The IR spectra of $\mathrm{C}_{6} \mathrm{H}_{4}\left(\mathrm{CO}_{2} \mathrm{CH}_{2}\right) \mathrm{CO}_{2} \mathrm{CH}_{3}\left(1 \mathrm{C}\right.$, black, a), $\mathrm{C}_{6} \mathrm{H}_{5} \mathrm{CHC}_{6} \mathrm{H}_{4} \mathrm{OH}$ (1D, black, b) and $\mathrm{C}_{6} \mathrm{H}_{5} \mathrm{CH}_{2} \mathrm{C}_{6} \mathrm{H}_{4} \mathrm{O}$ (3D, dark red, b), calculated using the B3LYP/6-311++G(d,p) approach.

As it is expected, the spectra, presented in Figures 3a and 3b, are very close those reported for the Dimethyl phthalate and p-Benzylphenol. In the case of Dimethyl phthalate, the difference between its measured spectrum [33] and the spectrum, calculated for the structure 1C, is mainly observed at $\sim 300$ and $\sim 1020 \mathrm{~cm}^{-1}$. This difference corresponds, respectively, to the frequencies of the angular vibration of [?]HCH group and to the vibration of $\mathrm{RC}-\mathrm{OCH}_{2}$ bonds.

In the case of p-Benzylphenol, the main difference between its measured spectrum [33] and the spectra, calculated for the most thermochemically favorable structures $1 \mathrm{D} / 3 \mathrm{D}$, is due to the vibration of C-H bonds of methylene group $\left(\sim 3020\right.$ and $\left.\sim 3050 \mathrm{~cm}^{-1}\right)$, not presented in these radicals. In addition, the calculated spectrum of $\mathrm{C}_{6} \mathrm{H}_{5} \mathrm{CH}_{2} \mathrm{C}_{6} \mathrm{H}_{4} \mathrm{O}$ (structure 3D), also presented on Figure 3b, does not have absorption at $\sim 3840 \mathrm{~cm}^{-1}$, corresponded to the vibration of $\mathrm{O}-\mathrm{H}$ bond, but demonstrates the vibration of $\mathrm{CH}_{2}$ group at $\sim 3020$ and $\sim 3050 \mathrm{~cm}^{-1}$.

As a result, it can be concluded, that the calculated vibration frequencies must not introduce significant error to the values of entropies, presented above (Table 7). This conclusion is due to the consistency between the calculated IR spectra of radicals and the spectra, reported for the Dimethyl phthalate and p-Benzylphenol.

\subsubsection{Temperature dependencies}

Temperature dependencies of the main thermochemical properties of the most stable radicals $(1 \mathrm{C}, 1 \mathrm{D}$ and 3D), considered in the present work, are determined using their values of $\Delta_{\mathrm{f}} H^{\circ}{ }_{298.15}$, determined above, as well as the B3LYP/6-311++G(d,p) geometry and vibration frequencies, scaled according to NIST recommendations [42]. In addition, the temperature dependencies for their isomers with the lowest values of $\Delta_{\mathrm{f}} \mathrm{H}^{\mathrm{o}}{ }_{298.15}$ (structures $5 \mathrm{C}$ and $4 \mathrm{D}$ ) or the highest corrected CBS-4M values of $S{ }^{\circ}{ }_{298.15}$ (6C and 17D) are also determined. The results of these calculations are presented in Tables 8 and 9 .

Table 8. Temperature dependencies of the thermochemical properties $\left(\left(\mathrm{C}_{\mathrm{p}}\right)_{\mathrm{T}}\left(\mathrm{J} /(\mathrm{mol} \mathrm{K}), \mathrm{S}^{\mathrm{o}} \mathrm{T}(\mathrm{J} /(\mathrm{mol}\right.\right.$ $\left.\mathrm{K}), \Delta_{\mathrm{f}} H^{{ }^{\circ}}{ }_{\mathrm{T}}(\mathrm{kJ} / \mathrm{mol}), \Delta_{\mathrm{f}} G{ }^{{ }^{\circ}}{ }_{\mathrm{T}}(\mathrm{kJ} / \mathrm{mol})\right)$ of structures (1C) and (1D), determined using the B3LYP/6$311++\mathrm{G}(\mathrm{d}, \mathrm{p})$ geometries and scaled $(0.996)$ frequencies. 


\begin{tabular}{|c|c|c|c|c|c|c|c|c|}
\hline$T, K$ & $(1 \mathrm{C})$ & $(1 \mathrm{C})$ & $(1 \mathrm{C})$ & $(1 \mathrm{C})$ & (1D) & (1D) & (1D) & (1D) \\
\hline & $\left(C_{\mathrm{p}}\right)_{\mathrm{T}}$ & $S^{\mathrm{o}}{ }_{\mathrm{T}}$ & $\Delta_{\mathrm{f}} H^{\mathrm{o}}{ }_{\mathrm{T}}$ & $\Delta_{\mathrm{f}} G^{\mathrm{o}} \mathrm{T}$ & $\left(C_{\mathrm{p}}\right)_{\mathrm{T}}$ & $S^{\mathrm{o}}{ }_{\mathrm{T}}$ & $\Delta_{\mathrm{f}} H_{\mathrm{T}}^{\mathrm{o}}$ & $\Delta_{\mathrm{f}} G^{\mathrm{O}} \mathrm{T}$ \\
\hline 0 & 0.000 & 0.000 & -378.286 & -378.286 & 0 & 0 & 146.867 & 146.867 \\
\hline 100 & 101.900 & 324.844 & -391.628 & -343.167 & 77.241 & 306.332 & 133.549 & 168.225 \\
\hline 200 & 160.492 & 414.129 & -399.617 & -291.413 & 135.274 & 376.865 & 123.545 & 206.889 \\
\hline 298.15 & 214.072 & 488.215 & -406.1 & -236.754 & 201.207 & 443.074 & 114.700 & 249.858 \\
\hline 300 & 215.070 & 489.542 & -406.21 & -235.836 & 202.453 & 444.322 & 114.547 & 250.561 \\
\hline 400 & 266.428 & 558.591 & -411.333 & -178.229 & 265.995 & 511.476 & 107.275 & 297.046 \\
\hline 500 & 310.251 & 622.906 & -414.961 & -119.504 & 318.946 & 576.732 & 101.773 & 345.160 \\
\hline 600 & 345.955 & 682.743 & -417.368 & -60.169 & 361.175 & 638.763 & 97.657 & 394.243 \\
\hline 700 & 374.897 & 738.322 & -418.737 & -0.51 & 394.893 & 697.065 & 94.686 & 443.929 \\
\hline 800 & 398.617 & 789.981 & -419.194 & 59.269 & 422.279 & 751.644 & 92.707 & 493.956 \\
\hline 900 & 418.321 & 838.104 & -418.862 & 119.071 & 444.93 & 802.729 & 91.587 & 544.196 \\
\hline 1000 & 434.872 & 883.060 & -417.851 & 178.787 & 463.938 & 850.619 & 91.205 & 594.504 \\
\hline 1100 & 448.894 & 925.183 & -416.278 & 238.384 & 480.058 & 895.614 & 91.436 & 644.834 \\
\hline 1200 & 460.851 & 964.768 & -414.234 & 297.809 & 493.833 & 937.99 & 92.181 & 695.111 \\
\hline 1300 & 471.102 & 1002.071 & -411.824 & 357.046 & 505.674 & 977.997 & 93.327 & 745.304 \\
\hline 1400 & 479.931 & 1037.315 & -409.125 & 416.106 & 515.903 & 1015.855 & 94.790 & 795.423 \\
\hline 1500 & 487.571 & 1070.693 & -406.201 & 474.939 & 524.779 & 1051.758 & 96.507 & 845.396 \\
\hline 1600 & 494.210 & 1102.377 & -403.118 & 533.59 & 532.513 & 1085.879 & 98.402 & 895.272 \\
\hline 1700 & 500.002 & 1132.516 & -399.928 & 592.03 & 539.278 & 1118.37 & 100.420 & 945.005 \\
\hline 1800 & 505.077 & 1161.242 & -396.671 & 650.289 & 545.219 & 1149.366 & 102.515 & 994.628 \\
\hline 1900 & 509.540 & 1188.673 & -393.38 & 708.364 & 550.455 & 1178.988 & 104.662 & 1044.135 \\
\hline 2000 & 513.481 & 1214.911 & -390.084 & 766.261 & 555.089 & 1207.343 & 106.820 & 1093.518 \\
\hline 2100 & 516.975 & 1240.050 & -386.826 & 823.991 & 559.202 & 1234.527 & 108.946 & 1142.792 \\
\hline 2200 & 520.082 & 1264.173 & -383.612 & 881.581 & 562.868 & 1260.628 & 111.033 & 1191.981 \\
\hline 2300 & 522.856 & 1287.354 & -380.454 & 939.029 & 566.144 & 1285.722 & 113.072 & 1241.082 \\
\hline 2400 & 525.341 & 1309.660 & -377.382 & 996.323 & 569.083 & 1309.88 & 115.024 & 1290.074 \\
\hline 2500 & 527.573 & 1331.151 & -374.4 & 1053.499 & 571.727 & 1333.165 & 116.889 & 1338.999 \\
\hline 2600 & 529.585 & 1351.883 & -371.523 & 1110.56 & 574.113 & 1355.636 & 118.646 & 1387.850 \\
\hline 2700 & 531.405 & 1371.904 & -368.754 & 1167.504 & 576.272 & 1377.345 & 120.295 & 1436.624 \\
\hline 2800 & 533.054 & 1391.261 & -366.106 & 1224.358 & 578.231 & 1398.338 & 121.819 & 1485.356 \\
\hline 2900 & 534.554 & 1409.993 & -363.592 & 1281.111 & 580.013 & 1418.661 & 123.201 & 1534.025 \\
\hline 3000 & 535.920 & 1428.138 & -361.198 & 1337.792 & 581.639 & 1438.352 & 124.461 & 1582.660 \\
\hline
\end{tabular}

Table 9. Temperature dependencies of the thermochemical properties $\left(\left(\mathrm{C}_{\mathrm{p}}\right)_{\mathrm{T}}\left(\mathrm{J} /(\mathrm{mol} \mathrm{K}), \mathrm{S}^{\mathrm{o}} \mathrm{T}(\mathrm{J} /(\mathrm{mol} \mathrm{K})\right.\right.$, $\left.\Delta_{\mathrm{f}} H^{\circ}{ }_{\mathrm{T}}(\mathrm{kJ} / \mathrm{mol}), \Delta_{\mathrm{f}} G^{{ }^{\circ}}{ }_{\mathrm{T}}(\mathrm{kJ} / \mathrm{mol})\right)$ of structures $(3 \mathrm{D})$, determined using the B3LYP $/ 6-311++\mathrm{G}(\mathrm{d}, \mathrm{p})$ geometries and scaled (0.996) frequencies.

\begin{tabular}{lllll}
\hline$T, K$ & $(3 \mathrm{D})$ & $(3 \mathrm{D})$ & $(3 \mathrm{D})$ & $(3 \mathrm{D})$ \\
\hline & $\left(C_{\mathrm{p}}\right)_{\mathrm{T}}$ & $S^{\mathrm{o}} \mathrm{T}$ & $\Delta_{\mathrm{f}} H^{\mathrm{o}} \mathrm{T}$ & $\Delta_{\mathrm{f}} G^{\mathrm{o}} \mathrm{T}$ \\
0 & 0 & 0 & 167.966 & 167.966 \\
100 & 79.134 & 326.578 & 155.201 & 187.852 \\
200 & 131.937 & 396.629 & 145.097 & 224.488 \\
298.15 & 195.791 & 461.027 & 135.800 & 265.605 \\
300 & 197.021 & 462.242 & 135.637 & 266.275 \\
400 & 260.53 & 527.797 & 127.809 & 311.052 \\
500 & 314.251 & 591.909 & 121.796 & 357.595 \\
600 & 357.456 & 653.17 & 117.259 & 405.201 \\
700 & 392.128 & 710.97 & 113.964 & 453.473
\end{tabular}




\begin{tabular}{lllll}
\hline$T, K$ & $(3 \mathrm{D})$ & $(3 \mathrm{D})$ & $(3 \mathrm{D})$ & $(3 \mathrm{D})$ \\
\hline 800 & 420.355 & 765.236 & 111.752 & 502.127 \\
900 & 443.706 & 816.137 & 110.476 & 551.017 \\
1000 & 463.271 & 863.928 & 110.001 & 599.990 \\
1100 & 479.819 & 908.88 & 110.187 & 648.992 \\
1200 & 493.914 & 951.25 & 110.925 & 697.942 \\
1300 & 505.988 & 991.274 & 112.092 & 746.808 \\
1400 & 516.382 & 1029.161 & 113.594 & 795.598 \\
1500 & 525.371 & 1065.102 & 115.366 & 844.239 \\
1600 & 533.179 & 1099.264 & 117.323 & 892.779 \\
1700 & 539.989 & 1131.796 & 119.410 & 941.172 \\
1800 & 545.953 & 1162.834 & 121.578 & 989.450 \\
1900 & 551.198 & 1192.495 & 123.798 & 1037.608 \\
2000 & 555.828 & 1220.888 & 126.031 & 1085.639 \\
2100 & 559.93 & 1248.108 & 128.230 & 1133.557 \\
2200 & 563.579 & 1274.242 & 130.390 & 1181.386 \\
2300 & 566.836 & 1299.368 & 132.499 & 1229.123 \\
2400 & 569.752 & 1323.555 & 134.519 & 1276.749 \\
2500 & 572.373 & 1346.867 & 136.450 & 1324.306 \\
2600 & 574.734 & 1369.363 & 138.270 & 1371.785 \\
2700 & 576.869 & 1391.094 & 139.980 & 1419.186 \\
2800 & 578.804 & 1412.109 & 141.562 & 1466.541 \\
2900 & 580.563 & 1432.451 & 143.001 & 1513.832 \\
3000 & 582.166 & 1452.161 & 144.314 & 1561.087 \\
\hline & & & &
\end{tabular}

The slight differences, observed between the values of ${ }^{\circ}{ }^{\circ}{ }_{298.15}(\mathrm{Y}, \mathrm{CALC})_{\text {B3LYP }}$ (Table 7) and the values of $S$ ${ }^{\circ}{ }_{\mathrm{T}}($ at $T=298.15 \mathrm{~K}$, Tables 8,9 and SI, Note 8 (Tables A and B)), are due to the using, in the last case, of the scaling factor, recommended by NIST database [41], for the correction of vibration frequencies.

As can be seen, in most of the cases, the increase of temperature does not qualitatively affecting the equilibrium distribution between the radicals. Thus, the same structures of these radicals (1C, 1D-3D) are the most thermochemically favorable at temperatures 298.15 and $3000 \mathrm{~K}$. The significant difference is only observed between the structures $1 \mathrm{D}$ and $3 \mathrm{D}$. In this case, the most thermochemically stable structure, predicted for the temperatures above $2000 \mathrm{~K}$, is $3 \mathrm{D}$, but is not the structures $1 \mathrm{D}$ and $2 \mathrm{D}$.

The small inconsistency between the values of $S{ }^{\circ}{ }_{298.15}$, recommended in the present work (Table 7, in bold), and their, not corrected, B3LYP values, used for the reported temperature dependencies, is insignificant and can be adjusted by addition of the values of $S{ }^{\circ}{ }_{298.15}(\mathrm{Y}, \mathrm{CORR})_{\mathrm{CBS}-4 \mathrm{M}}-S^{\mathrm{O}_{298.15}}(\mathrm{Y}, \mathrm{CALC})_{\mathrm{B} 3 \mathrm{LYP}}$ to the scaled values of $S{ }^{\circ} \mathrm{T}(\mathrm{Y}, \mathrm{CALC})_{\mathrm{B} 3 \mathrm{LYP}}$. Thus, the significant differences between the values of $S{ }^{\circ}{ }_{3000}(\mathrm{Y}$, CALC) $-S{ }^{\circ}{ }_{298.15}$ (Y, CALC), determined using the different QM approaches, are not observed (Table 10).

Table 10. Temperature effect on the values of $S^{\circ}$ T of the most thermochemically stable structures 1C, 1D and 3D.

\begin{tabular}{llll}
\hline $\mathrm{QM}$ & $S^{\mathrm{o}}{ }_{3000}(\mathrm{Y}, \mathrm{CALC})-S^{\mathrm{o}}{ }_{298.15}(\mathrm{Y}, \mathrm{CALC}), \mathrm{J} /(\mathrm{mol} \mathrm{K})$ & $S^{\mathrm{o}}{ }_{3000}(\mathrm{Y}, \mathrm{CALC})-S^{\mathrm{o}}{ }_{298.15}(\mathrm{Y}, \mathrm{CALC}), \mathrm{J} /(\mathrm{mol} \mathrm{K})$ & $S^{\mathrm{o}}{ }_{30}$ \\
\hline & $1 \mathrm{C}$ & $1 \mathrm{D}$ & $3 \mathrm{D}$ \\
$\mathrm{B} 3 \mathrm{LYP}$ & 939.9 & 995.3 & 991.1 \\
CBS-4M & 935.2 & 1000.4 & 992.2 \\
M06-2X & 932.6 & 989.9 & 986.0 \\
\hline
\end{tabular}


The NASA polynomial form for the most thermochemically favorable structures are reported below.

\begin{tabular}{lr}
\hline C6H4(CO2CH2) H 9C 10O 4 0g 300.00 5000.00 1000.00 & 1 \\
\hline $2.61925331 \mathrm{E}+01$ 3.90153651E-02-1.53874921E-05 2.77271165E-09-1.87516226E-13 & 2 \\
$-6.06140178 \mathrm{E}+04-1.06885434 \mathrm{E}+02$ 7.34068835E-01 1.00177216E-01-5.44073621E-05 & 3 \\
$4.70975205 \mathrm{E}-09$ 1.05223290E-11-5.30311753E+04 2.71041634E+01 & 4 \\
\hline
\end{tabular}

\begin{tabular}{lr}
\hline C6H5CHC6H4OH_1D H 11C 13O 1 0g 300.00 5000.00 1000.00 & 1 \\
\hline $2.58261199 \mathrm{E}+01$ 4.46658587E-02-1.75098213E-05 3.14286073E-09-2.11992719E-13 & 2 \\
1.42429281E+03-1.12958631E+02-8.73432400E+00 1.38156180E-01-1.00164238E-04 & 3 \\
$2.18497804 \mathrm{E}-08$ 4.70746911E-12 1.10969737E+04 6.61076246E+01 & 4 \\
\hline
\end{tabular}

\begin{tabular}{lr}
\hline C6H5CH2C6H4O_3D H 11C 13O 1 0g 300.00 5000.00 1000.00 & 1 \\
\hline $2.49221685 \mathrm{E}+01$ 4.60393038E-02-1.81770211E-05 3.27776273E-09-2.21787754E-13 & 2 \\
$4.09498659 \mathrm{E}+03-1.06193269 \mathrm{E}+02-8.15775498 \mathrm{E}+001.29079520 \mathrm{E}-01-7.81334086 \mathrm{E}-05$ & 3 \\
$1.63173469 \mathrm{E}-091.13165088 \mathrm{E}-111.37083149 \mathrm{E}+046.68738078 \mathrm{E}+01$ & 4 \\
\hline
\end{tabular}

\subsection{Potentially important reactions of the formation of $Y$ radicals.}

As it is shown above, the abstraction of $\mathrm{H}$ atom from the $\mathrm{CH}_{\mathrm{n}}$ group of the considered compounds (Dimethyl phthalate and p-Benzylphenol) is the most thermochemically favorable pathway. In the case of Dimethyl phthalate this conclusion agrees with the results of work $[16,17]$, which demonstrate that the value of BDE of $\mathrm{C}_{6} \mathrm{H}_{5} \mathrm{R}-\mathrm{H}$ increase according to the following order $\mathrm{BDE}(\mathrm{R}=\mathrm{O})<\mathrm{BDE}\left(\mathrm{R}=\mathrm{CH}_{2}\right)<\operatorname{BDE}\left(\mathrm{R}=\mathrm{OCH}_{2}\right)$ $<\operatorname{BDE}\left(\mathrm{C}_{6} \mathrm{H}_{5}-\mathrm{H}\right.$, no R). However, in the present work, some contradiction with this order is observed for p-Benzylphenol. Thus, the value of $\operatorname{BDE}\left(\mathrm{R}=\mathrm{C}_{6} \mathrm{H}_{5} \mathrm{CH}\right)$ is not higher, but is lower than the value of $\mathrm{BDE}(\mathrm{R}$ $=\mathrm{O})$. The noted discrepancy has explained above and is due to the conjugation of the electron of $\mathrm{CH}$ group with $\pi$-electrons of two aromatic rings.

As a result of the low value of $\mathrm{BDE}\left(\mathrm{R}=\mathrm{C}_{6} \mathrm{H}_{5} \mathrm{CH}\right)$, the reactions of $\mathrm{H}$ atom abstraction (transfer) from $\mathrm{CH}_{2}$ group of p-Benzylphenol can be very important for the pyrolysis, combustion and ignition processes. The values of $\Delta_{\mathrm{r}} H^{{ }^{\mathrm{o}}}{ }_{298.15}\left(\left(\mathrm{R}_{\mathrm{H}}\right)_{\mathrm{i}}\right), \Delta_{\mathrm{r}} S^{{ }^{\circ}}{ }_{298.15}\left(\left(\mathrm{R}_{\mathrm{H}}\right)_{\mathrm{i}}\right)$ and $\Delta_{\mathrm{r}} G^{{ }^{\circ}}{ }_{298.15}\left(\left(\mathrm{R}_{\mathrm{H}}\right)_{\mathrm{i}}\right)$ of the reactions of these components of the surrogate bio-oils, potentially important for the combustion chemistry, are presented in Table $11(j=$ $1-18)$.

The measured value of $\Delta_{\mathrm{f}} H^{\circ}{ }_{298.15}$ (Dimethyl phthalate, TAB) $=-606.1$ [18] and the estimated value of $\Delta_{\mathrm{f}} H$ ${ }_{298.15}(\mathrm{p} \text {-Benzylphenol })_{\text {REACMEAN }}(=-11.9 \pm 10 \mathrm{~kJ} / \mathrm{mol})$ are used for the determination of the values of $\Delta_{\mathrm{r}} H$ ${ }^{\circ}{ }_{298.15}\left(\left(\mathrm{R}_{\mathrm{H}}\right)_{\mathrm{i}}\right), \Delta_{\mathrm{r}} S^{\circ}{ }_{298.15}\left(\left(\mathrm{R}_{\mathrm{H}}\right)_{\mathrm{i}}\right)$ and $\Delta_{\mathrm{r}} G^{\circ}{ }_{298.15}\left(\left(\mathrm{R}_{\mathrm{H}}\right)_{\mathrm{i}}\right)$ of their reactions. The values of $\Delta_{\mathrm{f}} H^{\circ}{ }^{\circ}{ }_{298.15}$ and $S$ ${ }_{298.15}$ of radicals ( $\mathrm{NO}, \mathrm{NO}_{2}, \mathrm{HNO}, \mathrm{HNO}_{2}, \mathrm{NH}_{2}, \mathrm{NH}_{3}, \mathrm{NO}_{3}, \mathrm{HNO}_{3}, \mathrm{HO}_{2}, \mathrm{H}_{2} \mathrm{O}_{2}, \mathrm{CH}_{3} \mathrm{O}_{2}$ and $\mathrm{CH}_{3} \mathrm{O}_{2} \mathrm{H}$ ), used for the calculations of the $\Delta_{\mathrm{r}} H^{\circ}{ }_{298.15}\left(\left(\mathrm{R}_{\mathrm{H}}\right)_{\mathrm{j}}\right), \Delta_{\mathrm{r}} S{ }^{{ }^{\circ}}{ }_{298.15}\left(\left(\mathrm{R}_{\mathrm{H}}\right)_{\mathrm{j}}\right)$ and $\Delta_{\mathrm{r}} G^{{ }^{\circ}}{ }_{298.15}\left(\left(\mathrm{R}_{\mathrm{H}}\right)_{\mathrm{j}}\right)$, are taken from JANAF-NIST [48] and Burcat [37] databases.

Table 11. The values of $\Delta_{\mathrm{r}} H^{{ }^{\circ}}{ }_{298.15}\left(\left(\mathrm{R}_{\mathrm{H}}\right)_{\mathrm{j}}\right), \Delta_{\mathrm{r}} S{ }^{{ }^{\circ}}{ }_{298.15}\left(\left(\mathrm{R}_{\mathrm{H}}\right)_{\mathrm{j}}\right)$ and $\Delta_{\mathrm{r}} G^{{ }^{\circ}}{ }_{298.15}\left(\left(\mathrm{R}_{\mathrm{H}}\right)_{\mathrm{j}}\right)$ of reactions potentially important for the combustion chemistry and pyrolysis of the compounds of the considered surrogate bio-oil, determined using the tabulated (SI, Note 1 ) and calculated (Tables 5 and 7) values of $\Delta_{\mathrm{f}} H^{\circ}{ }_{298.15}$ and $S^{\circ}{ }_{298.15}$.

\begin{tabular}{llll}
\hline$j$ & Reactions $\left(\mathrm{R}_{\mathrm{H}}\right)_{\mathrm{j}}$ & $\Delta_{\mathrm{r}} H^{\mathrm{o}}{ }_{298.15}\left(\left(\mathrm{R}_{\mathrm{H}}\right)_{\mathrm{j}}\right), \mathrm{kJ} / \mathrm{mol}$ & $\Delta_{\mathrm{r}} S^{\mathrm{o}}{ }_{298.15}($ \\
\hline 1 & $\mathrm{CH}_{3}+\mathrm{C}_{6} \mathrm{H}_{4}\left((\mathrm{CO}) \mathrm{OCH}_{3}\right)_{2}-\mathrm{CH}_{4}+\mathrm{CH}_{2} \mathrm{O}(\mathrm{CO}) \mathrm{C}_{6} \mathrm{H}_{4}\left((\mathrm{CO}) \mathrm{OCH}_{3}\right)$ & -23.5 & -3.3
\end{tabular}




\begin{tabular}{|c|c|c|c|}
\hline$j$ & Reactions $\left(\mathrm{R}_{\mathrm{H}}\right)_{\mathrm{j}}$ & $\Delta_{\mathrm{r}} H^{\mathrm{o}}{ }_{298.15}\left(\left(\mathrm{R}_{\mathrm{H}}\right)_{\mathrm{j}}\right), \mathrm{kJ} / \mathrm{mol}$ & $\Delta_{\mathrm{r}} S^{\mathrm{o}}{ }_{298.15}$ \\
\hline 2 & $\mathrm{NO}_{3}+\mathrm{C}_{6} \mathrm{H}_{4}\left((\mathrm{CO}) \mathrm{OCH}_{3}\right)_{2}-\mathrm{HNO}_{3}+\mathrm{CH}_{3} \mathrm{C}_{6} \mathrm{H}_{3}(\mathrm{O}) \mathrm{CH}_{3}$ & -8.5 & 18.4 \\
\hline 3 & $\mathrm{OH}+\mathrm{C}_{6} \mathrm{H}_{4}\left((\mathrm{CO}) \mathrm{OCH}_{3}\right)_{2}-\mathrm{H}_{2} \mathrm{O}+\mathrm{CH}_{2} \mathrm{O}(\mathrm{CO}) \mathrm{C}_{6} \mathrm{H}_{4}\left((\mathrm{CO}) \mathrm{OCH}_{3}\right)$ & -83.7 & 9.7 \\
\hline 4 & $\mathrm{H}+\mathrm{C}_{6} \mathrm{H}_{4}\left((\mathrm{CO}) \mathrm{OCH}_{3}\right)_{2}-\mathrm{H}_{2}+\mathrm{CH}_{2} \mathrm{O}(\mathrm{CO}) \mathrm{C}_{6} \mathrm{H}_{4}\left((\mathrm{CO}) \mathrm{OCH}_{3}\right)$ & -20.9 & 20.6 \\
\hline 5 & $\mathrm{NO}_{2}+\mathrm{C}_{6} \mathrm{H}_{4}\left((\mathrm{CO}) \mathrm{OCH}_{3}\right)_{2}-\mathrm{HNO}_{2}+\mathrm{CH}_{2} \mathrm{O}(\mathrm{CO}) \mathrm{C}_{6} \mathrm{H}_{4}\left((\mathrm{CO}) \mathrm{OCH}_{3}\right)$ & 87.7 & 14.0 \\
\hline 6 & $\mathrm{NO}+\mathrm{C}_{6} \mathrm{H}_{4}\left((\mathrm{CO}) \mathrm{OCH}_{3}\right)_{2}-\mathrm{HNO}+\mathrm{CH}_{2} \mathrm{O}(\mathrm{CO}) \mathrm{C}_{6} \mathrm{H}_{4}\left((\mathrm{CO}) \mathrm{OCH}_{3}\right)$ & 206.4 & 14.0 \\
\hline 7 & $\mathrm{NH}_{2}+\mathrm{C}_{6} \mathrm{H}_{4}\left((\mathrm{CO}) \mathrm{OCH}_{3}\right)_{2}-\mathrm{NH}_{3}+\mathrm{CH}_{2} \mathrm{O}(\mathrm{CO}) \mathrm{C}_{6} \mathrm{H}_{4}\left((\mathrm{CO}) \mathrm{OCH}_{3}\right)$ & -39.2 & 2.7 \\
\hline 8 & $\mathrm{HO}_{2}+\mathrm{C}_{6} \mathrm{H}_{4}\left((\mathrm{CO}) \mathrm{OCH}_{3}\right)_{2}-\mathrm{H}_{2} \mathrm{O}_{2}+\mathrm{CH}_{2} \mathrm{O}(\mathrm{CO}) \mathrm{C}_{6} \mathrm{H}_{4}\left((\mathrm{CO}) \mathrm{OCH}_{3}\right)$ & 58.9 & 8.4 \\
\hline 9 & $\mathrm{CH}_{3} \mathrm{O}_{2}+\mathrm{C}_{6} \mathrm{H}_{4}\left((\mathrm{CO}) \mathrm{OCH}_{3}\right)_{2}-\mathrm{CH}_{3} \mathrm{O}_{2} \mathrm{H}+\mathrm{CH}_{2} \mathrm{O}(\mathrm{CO}) \mathrm{C}_{6} \mathrm{H}_{4}\left((\mathrm{CO}) \mathrm{OCH}_{3}\right)$ & 58.5 & 20.9 \\
\hline 10 & $\mathrm{CH}_{3}+\mathrm{C}_{6} \mathrm{H}_{5} \mathrm{CH}_{2} \mathrm{C}_{6} \mathrm{H}_{4} \mathrm{OH}-\mathrm{CH}_{4}+\mathrm{C}_{6} \mathrm{H}_{5} \mathrm{CHC}_{6} \mathrm{H}_{4} \mathrm{OH}$ & -102.9 & -12.3 \\
\hline 11 & $\mathrm{NO}_{3}+\mathrm{C}_{6} \mathrm{H}_{5} \mathrm{CH}_{2} \mathrm{C}_{6} \mathrm{H}_{4} \mathrm{OH}-\mathrm{HNO}_{3}+\mathrm{C}_{6} \mathrm{H}_{5} \mathrm{CHC}_{6} \mathrm{H}_{4} \mathrm{OH}$ & -87.9 & 9.4 \\
\hline 12 & $\mathrm{OH}+\mathrm{C}_{6} \mathrm{H}_{5} \mathrm{CH}_{2} \mathrm{C}_{6} \mathrm{H}_{4} \mathrm{OH}-\mathrm{H}_{2} \mathrm{O}+\mathrm{C}_{6} \mathrm{H}_{5} \mathrm{CHC}_{6} \mathrm{H}_{4} \mathrm{OH}$ & -163.1 & 0.7 \\
\hline 13 & $\mathrm{H}+\mathrm{C}_{6} \mathrm{H}_{5} \mathrm{CH}_{2} \mathrm{C}_{6} \mathrm{H}_{4} \mathrm{OH}-\mathrm{H}_{2}+\mathrm{C}_{6} \mathrm{H}_{5} \mathrm{CHC}_{6} \mathrm{H}_{4} \mathrm{OH}$ & -100.3 & 11.6 \\
\hline 14 & $\mathrm{NO}_{2}+\mathrm{C}_{6} \mathrm{H}_{5} \mathrm{CH}_{2} \mathrm{C}_{6} \mathrm{H}_{4} \mathrm{OH}-\mathrm{HNO}_{2}+\mathrm{C}_{6} \mathrm{H}_{5} \mathrm{CHC}_{6} \mathrm{H}_{4} \mathrm{OH}$ & 8.3 & 5.0 \\
\hline 15 & $\mathrm{NO}+\mathrm{C}_{6} \mathrm{H}_{5} \mathrm{CH}_{2} \mathrm{C}_{6} \mathrm{H}_{4} \mathrm{OH}-\mathrm{HNO}+\mathrm{C}_{6} \mathrm{H}_{5} \mathrm{CHC}_{6} \mathrm{H}_{4} \mathrm{OH}$ & 127.0 & 5.6 \\
\hline 16 & $\mathrm{NH}_{2}+\mathrm{C}_{6} \mathrm{H}_{5} \mathrm{CH}_{2} \mathrm{C}_{6} \mathrm{H}_{4} \mathrm{OH}-\mathrm{NH}_{3}+\mathrm{C}_{6} \mathrm{H}_{5} \mathrm{CHC}_{6} \mathrm{H}_{4} \mathrm{OH}$ & -118.6 & -6.3 \\
\hline 17 & $\mathrm{HO}_{2}+\mathrm{C}_{6} \mathrm{H}_{5} \mathrm{CH}_{2} \mathrm{C}_{6} \mathrm{H}_{4} \mathrm{OH}-\mathrm{H}_{2} \mathrm{O}_{2}+\mathrm{C}_{6} \mathrm{H}_{5} \mathrm{CHC}_{6} \mathrm{H}_{4} \mathrm{OH}$ & -20.5 & -0.6 \\
\hline 18 & $\mathrm{CH}_{3} \mathrm{O}_{2}+\mathrm{C}_{6} \mathrm{H}_{5} \mathrm{CH}_{2} \mathrm{C}_{6} \mathrm{H}_{4} \mathrm{OH}-\mathrm{CH}_{3} \mathrm{O}_{2} \mathrm{H}+\mathrm{C}_{6} \mathrm{H}_{5} \mathrm{CHC}_{6} \mathrm{H}_{4} \mathrm{OH}$ & -20.9 & 11.9 \\
\hline
\end{tabular}

As can be seen, the reactions of $\mathrm{NO}$ and $\mathrm{NO}_{2}((5),(6),(14)$ and (15)) with Dimethyl phthalate and p-Benzylphenol are not thermochemically favorable. At the same time, the reaction of $\mathrm{NO}_{2}$ with pBenzylphenol is only slightly endothermic, and rather should be considered as the thermoneutral. The slight exothermic effect, predicted for the reaction of $\mathrm{NO}_{3}$ with Dimethyl phthalate $(j=2)$, must also be considered as an indication of thermoneutral reaction. However, the contribution of these reactions to the combustion or atmospheric chemistry must be insignificant, due to their undetectable gas phase concentration in the atmosphere and to their complete oxidation under combustion conditions at the moment of $\mathrm{NO}_{2}$ or $\mathrm{NO}_{3}$ formation. However, their heterogeneous reactions on the surface of atmospheric aerosols can be valuable. The last statement also corrects for the thermochemically favorable reactions $(j=1,3,4,7,10-13$, 16-18), considered in the present work.

Moreover, the thermochemically favorable reactions are important for the determination of mechanisms of combustion of Dimethyl phthalate and p-Benzylphenol. Thus, the results of the present study indicate that both of these compounds can be oxidized by the $\mathrm{H}, \mathrm{OH}, \mathrm{CH}_{3}$ and $\mathrm{NH}_{2}$ radicals, formed during the ignition and combustion of fuels, contained them. The thermochemistry of these reactions is more favorable than those for the alkanes.

At the same time, the reactions with peroxy radicals (8) and (9), which are very important for the propagation of oxidation of Dimethyl phthalate, are not thermochemically favorable. However, the slightly lower values of $\Delta_{\mathrm{r}} \mathrm{H}^{\mathrm{o}}{ }_{298.15}\left(\left(\mathrm{R}_{\mathrm{H}}\right)_{\mathrm{i}}\right)$ and $\Delta_{\mathrm{r}} G{ }^{{ }^{\circ}}{ }_{298.15}\left(\left(\mathrm{R}_{\mathrm{H}}\right)_{\mathrm{i}}\right.$ than those for the reaction of $\mathrm{CH}_{3} \mathrm{OO}$ with $\mathrm{CH}_{4}$, indicate that its addition to the alkane fuel must decrease the ignition delay and temperature of ignition, as well as increase the rate of combustion. The even higher effect on combustion, according to the results of the present study, is expected for the addition of p-Benzylphenol to the fuels. Thus, the reactions of $\mathrm{HO}_{2}$ and $\mathrm{CH}_{3} \mathrm{O}_{2}$ with p-Benzylphenol are thermochemically favorable. As a results, the rate of propagation reactions must arising, as well as the temperature of ignition and ignition delay should decreasing, compared with both alkanes and Dimethyl phthalate fuels.

The reactions of $\mathrm{C}_{6} \mathrm{H}_{5} \mathrm{CHC}_{6} \mathrm{H}_{4} \mathrm{OH}$ formation and decomposition are important not only for the combustion chemistry of fuels and for the heterogeneous processes in the atmosphere, but also for the conversion of lignine biomass to the bio-oil or others products. Thus, the p-Benzylphenol is the small piece of lignine that contains the main its functional groups. As a result, the detailed radical driven chemistry of its thermal decomposition can also be applied to the mechanism of thermal decomposition of lignines. 
The effect of the temperature on thermochemistry of these reactions is also estimated in the present work. However, it is found that this effect is not significant up to $T=3000 \mathrm{~K}$, and qualitatively corresponds those results, demonstrated above for the standard conditions at $T=298.15 \mathrm{~K}$.

\section{CONCLUSIONS}

In the present work, the structures of the most thermochemically stable radicals (1C, 1D and 3D), formed by the reactions of abstraction of $\mathrm{H}$ atom from Dimethyl phthalate and p-Benzylphenol, are determined. It is found that the most thermochemically favorable pathways for the reactions of abstraction of $\mathrm{H}$ atom are, respectively, formation $\mathrm{OCH}_{2}{ }^{*}$ and $\mathrm{CH}^{*}$ groups.

The values of $\Delta_{\mathrm{f}} H^{\mathrm{o}}{ }_{298.15}(1 \mathrm{C})_{\text {MEAN }}$ and $\Delta_{\mathrm{f}} H^{\circ}{ }^{\mathrm{o}}{ }_{298.15}(1 \mathrm{D})_{\text {MEAN }}$ of the most thermochemically stable products of $\mathrm{H}$ atom abstraction of Dimethyl phthalate and p-Benzylphenol, determined in the present study using the corrected thermochemistry of atomization reactions, correspond, respectively, to $-406.1 \pm 3( \pm 3 \mathrm{SE})$ and $114.1 \pm 5( \pm 3 \mathrm{SE}) \mathrm{kJ} / \mathrm{mol}$. These values are consistent with those values, determined using the corrected thermochemistry of the homodesmotic reactions. Thus, nearly the same values of $\Delta_{\mathrm{f}} H^{\circ}{ }_{298.15}(1 \mathrm{C})_{\mathrm{REACMEAN}}=$ $-405.7 \pm 5( \pm 3 \mathrm{SE}) \mathrm{kJ} / \mathrm{mol}$ and $\Delta_{\mathrm{f}} H{ }^{\circ}{ }_{298.15}(1 \mathrm{D})_{\mathrm{REACMEAN}}=114.7 \pm 0.4( \pm 3 \mathrm{SE})$ are calculated. The values of $\Delta_{\mathrm{f}} H^{\circ}{ }^{\circ}{ }_{298.15}(1 \mathrm{C})_{\mathrm{MEAN}}=-406.1 \pm 3( \pm 3 \mathrm{SE}) \mathrm{kJ} / \mathrm{mol}$ and $\Delta_{\mathrm{f}} H^{\circ}{ }^{\circ}{ }_{298.15}(1 \mathrm{D})_{\mathrm{REACMEAN}}=114.7 \pm 0.4( \pm 3 \mathrm{SE})$ $\mathrm{kJ} / \mathrm{mol}$, demonstrated the lowest uncertainties ranges, are considered as the most consistent and reliable.

The contribution of other isomers to the integral values of thermochemical properties of these radicals, as well as to their IR spectra, is insignificant at room temperature. Thus, the values of $\Delta_{\mathrm{f}} H^{\circ}{ }_{298.15}(5 \mathrm{C})_{\mathrm{MEAN}}(=$ $-348.4 \pm 3( \pm 3 \mathrm{SE}) \mathrm{kJ} / \mathrm{mol}), \Delta_{\mathrm{f}} H^{\mathrm{o}}{ }_{298.15}(3 \mathrm{D})_{\mathrm{MEAN}}(=136.5 \pm 11( \pm 3 \mathrm{SE}) \mathrm{kJ} / \mathrm{mol})$ and $\Delta_{\mathrm{f}} H^{\circ}{ }_{298.15}(4 \mathrm{D})_{\mathrm{MEAN}}(=$ $237.9 \pm 11( \pm 3 \mathrm{SE}) \mathrm{kJ} / \mathrm{mol})$, determined using the thermochemistry of atomization reactions, as well as their values of $\Delta_{\mathrm{f}} H^{\circ}{ }_{298.15}(5 \mathrm{C})_{\text {REACMEAN }}(=-352.0 \pm 10( \pm 3 \mathrm{SE}) \mathrm{kJ} / \mathrm{mol}), \Delta_{\mathrm{f}} H^{{ }^{\circ}}{ }_{298.15}(3 \mathrm{D})_{\text {REACMEAN }}(=135.8 \pm 5$ $( \pm 3 \mathrm{SE}) \mathrm{kJ} / \mathrm{mol})$ and $\Delta_{\mathrm{f}} H^{\circ}{ }_{298.15}(4 \mathrm{D})_{\mathrm{REACMEAN}}(=241.4 \pm 10( \pm 3 \mathrm{SE}) \mathrm{kJ} / \mathrm{mol})$, calculated for these tautomers using the thermochemistry of homodesmotic reactions, are closest to those values of the most thermochemically stable radicals $1 \mathrm{C}$ and $1 \mathrm{D}$, produced during the abstraction of $\mathrm{H}$ atom from Dimethyl phthalate and p-Benzylphenol. However, even in this case, the differences between their values of $\Delta_{\mathrm{f}} H$ ${ }^{\circ}{ }_{298.15}(\mathrm{Y})_{\text {MEAN }}$ (or $\Delta_{\mathrm{f}} H^{\mathrm{o}}{ }_{298.15}(\mathrm{Y})_{\text {REACMEAN }}$ ) and the corresponded them values of $\Delta_{\mathrm{f}} H^{\mathrm{o}}{ }_{298.15}(1 \mathrm{C})_{\text {MEAN and }}$

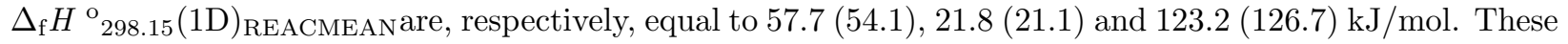
values are significantly larger than the difference between their values of entropies that don't exceeding 19 $\mathrm{J} /(\mathrm{mol} \mathrm{K})(19 \times 0.29815=5.7 \mathrm{~kJ} / \mathrm{mol})$ at $T=298.15 \mathrm{~K}$. At the same time, the importance of contribution of $3 \mathrm{D}$ structure to the distribution of isomers arises with the temperature, and became significant at temperatures above $2000 \mathrm{~K}$.

The significant differences between the values of $S{ }^{\circ}{ }_{298.15}(\mathrm{Y})$, calculated using the B3LYP, M06-2X and CBS-4M approaches, are not observed. Since, the contribution of the internal rotations to the values of $S$ ${ }^{\circ}{ }_{298.15}$ is not calculated in the present study then the CBS-4M values of $S{ }^{\circ}{ }_{298.15}(1 \mathrm{C}, \mathrm{CORR})=505.5 \pm 16$ $( \pm 2 \mathrm{SE}) \mathrm{J} /(\mathrm{mol} \mathrm{K})$ and $S^{\circ}{ }^{\circ}{ }_{298.15}(1 \mathrm{D}, \mathrm{CORR})=460.6 \pm 16( \pm 2 \mathrm{SE}) \mathrm{J} /(\mathrm{mol} \mathrm{K})$, determined using the correction dependencies [17], are recommended as the most accurate of calculated.

The temperature dependencies of thermochemical properties of considered compounds, calculated using the scaled B3LYP vibration frequencies, indicate that the structure 1D is the most thermochemically favorable product of $\mathrm{H}$ atom abstraction from p-Benzylphenol at temperatures below $2000 \mathrm{~K}$, while, the 3D structure is the most thermochemically stable for the temperatures above this value.

Analysis of the thermochemistry of reactions of $\mathrm{H}$ atom abstraction from Dimethyl phthalate and $\mathrm{p}$ Benzylphenol by the different radicals, formed during the pyrolysis of lignine, combustion of fossil fuels as well as produced in the atmosphere, indicate the high potential importance of reactions of p-Benzylphenol on the combustion and biomass pyrolysis, as well as their possible contribution to the atmospheric chemistry. In the last case, the contribution of these reactions on the heterogeneous chemistry of the atmospheric aerosols, contained lignine or its derivative, is assumed.

\section{AKNOWLEDGMENT}


The author is grateful to the Ministry of Education and Science of the Russian Federation (AAAA-A20120011390097-9) and (AAAA-A20-120011390099-3) for support of this work, as well as to Reviewers for the important and valuable comments.

\section{REFERENCES}

1. Czernik S., Bridgwater A.V. Overview of applications of biomass fast pyrolysis oil. Energy Fuels. 18 (2004) 590-598

2. Piskorz J., Scott D.S., Radlien D. Pyrolysis Oils from Biomass: Producing Analyzing and Upgrading; ACS: Washington, DC, 1988. pp. 167-178

3. Lee S-H., Eom M-S., Yoo K-S. The yields and composition of bio-oil produced from Quercus Acutissima in a bubbling fluidized bed pyrolyzer. J. Anal. Appl. Pyrolysis. 83 (2008) 110 - 114

4. Amen-Chen C., Pakdel H., Roy C. Production of monomeric phenols by thermochemical conversion of biomass: a review. Bioresource Technology. 79 (2001) $277-299$

5. Branca C., Giudicianni P., Di Blasi C. GC/MS characterization of liquids generated from lowtemperature pyrolysis of wood. Ind. Eng. Chem. Res. 42 (2003) $3190-3202$

6. Ba T., Chaala A., Garcia-Perez M. Colloidal properties of bio-oils obtained by vacuum pyrolysis of softwood bark. Storage stability. Energy \& Fuels. 18 (2004) $188-210$

7. Vispute T.P.; Huber G.W. Production of hydrogen, alkanes and polyols by aqueous phase processing of wood-derived pyrolysis oils. Green Chemistry. 11 (2009) 1433 - 1445

8. Poskrebyshev G.A., Wang H. Surrogate bio-oil. Catalysis Center for Energy Innovation (CCEI) Spring Symposium, March 28 - 29, 2010, University of Delaware, Newark, DE.

9. Poskrebyshev G.A. HIMIChESKIJ SOSTAV MODEL"NOGO BIOMASLA DLJa RASChJoTA I OPTIMIZACII PROIZVODSTVA BIOTOPLIV, tezisy konferencii «Aviadvigateli XXI veka», 24-27 nojabrja, 2015, Moskva, CIAM, S. 1016-1017 ISBN 978-5-94049-039-5

10. Poskrebyshev G.A. HIMIChESKIJ SOSTAV SURROGATNOJ SMESI DLJa ANALIZA PRODUKTOV I OPTIMIZACII USLOVIJ RADIACIONNO-HIMIChESKOJ PERERABOTKI BIOMASLA, 2015, VI Rossijskaja konferencija "Aktual'nye problemy himii vysokih jenergij”, sbornik statej, 20-22 oktjabrja, Moskva, izdatel'stvo "Granica", S. 296-298 ISBN 978-5-94691-797-1

11. R.J.L. Andon, D.P. Biddiscombe, J.D. Cox, R. Handley, D. Harrop, E.F.G. Herington, J.F. Martin Thermodynamic properties of organic oxygen compounds. Part I. Preparation and physical properties of pure phenol, cresols, and xylenols. J. Chem. Soc. (1960) 5246-5254

12. D.A. Ponomarev, T.P. Oleinikova, T.N. Masalitinova, ENTHALPY OF THE CREOSOL FORMATION. Izv. Vyssh. Uchebn. Zaved., Khimiya i Khimicheskaya Tekhnol. 30 (1987) 115-116

13. Ana R.R.P. Almeida, Vera L.S. Freitas, Joana I.S. Campos, Maria D.M.C. Ribeiro da Silva, Manuel J.S. Monte. Volatility and thermodynamic stability of vanillin. J. Chem. Thermodynamics. 128 (2019) $45-54$

14. Y. Maksimuk, D. Ponomarev, A. Sushkova, V. Krouk, I. Vasarenko, Z. Antonava, Standard molar enthalpy of formation of vanillin. J. Therm. Anal. Calorim. 131 (2018) 1721-1733

15. A.G. Baboul, L.A. Curtiss, P.C. Redfern, K. Raghavachari, Gaussian-3 theory using density functional geometries and zero-point energies. J. Chem. Phys. 110 (1999) 7650-7657

16. G.A. Poskrebyshev, Structures and thermochemical properties of phenoxy radicals, formed from components of the surrogate bio-oil. Gorenie I vzryv (Moskva) - Combustion, Explosion. 11 (2018) 34-42

17. G.A. Poskrebyshev, THE CBS VALUES OF $\Delta_{\mathrm{f}} \mathrm{H}^{\circ}{ }_{298.15}$ AND $S{ }^{\circ}{ }_{298.15}$ OF THE PHENOXY RADICALS, FORMED BY ABSTRACTION OF H ATOM FROM THE COMPONENTS OF SURROGATE BIO-OIL. Computational and Theoretical Chemistry. 1169 (2019) 112625

18. M.A. Roux, P. Jimenez, J.Z. Davalos, C. Turrion, H.Y. Afeefy, J.F. Liebman, Enthalpies of formation of methyl benzenecarboxylates. J. Chem. Soc. Faraday Trans. 94 (1998) 887-890

19. Y.V. Maksimuk, G.J. Kabo, V.V. Simirsky, A.A. Kozyro, V.M. Sevruk, Standard Enthalpies of Formation of Some Methyl Esters of Benzene Carboxylic Acids. J. Chem. Eng. Data. 43(3) (1998) 293-298

20. G. Bertholon, M. Giray, R. Perrin, M.F. Vincent-Falquet-Berny, No. 532. - Etude physicochimique 
des phenols. OX. - Ethanlpies de combustion et energies de resonance des alcoyl et aryphenols. Bull. Soc. Chim. France. (1971) 3180-3187

21. G.A. Poskrebyshev, THE STANDARD THERMOCHEMICAL PROPERTIES OF THE pBENZYLPHENOL AND DIMETHYL PHTHALATE, AND THEIR TEMPERATURE DEPENDENCIES. Computational and Theoretical Chemistry. 1171 (2021)

22. A. D. Becke, "Density-functional thermochemistry. III. The role of exact exchange," J. Chem. Phys., 98 (1993) 5648

23. Y. Zhao and D. G. Truhlar, "The M06 suite of density functionals for main group thermochemistry, thermochemical kinetics, noncovalent interactions, excited states, and transition elements: two new functionals and systematic testing of four M06-class functionals and 12 other functionals," Theor. Chem. Acc. , 120 (2008) 215

24. G.P.F. Wood, L. Radom, G.A. Petersson, E.C. Barnes, M.J. Frisch, and J.A. Montgomery Jr., A restricted-open-shell complete-basis-set model chemistry. J. Chem. Phys. 125 (2006) 094106

25. J.W. Ochterski, G.A. Petersson, and J.A. Montgomery Jr., A complete basis set model chemistry. V. Extensions to six or more heavy atoms. J. Chem. Phys. 104 (1996) 2598-619

26. C. Møller and M.S. Plesset. Note on an approximation treatment for many-electron systems. Phys. Rev. 46 (1934) 0618-22.

27. M.J. Frisch, M. Head-Gordon, and J.A. Pople, Direct MP2 gradient method. Chem. Phys. Lett. 166 (1990) 275-80

28. J.A. Pople, J.S. Binkley, and R. Seeger, Theoretical Models Incorporating Electron Correlation. Int. J. Quantum Chem. Suppl. Y-10 (1976) 1-19

29. K. Raghavachari and J.A. Pople, Approximate 4th-order perturbation-theory of electron correlation energy. Int. J. Quantum Chem. 14 (1978) 91-100

30. M.R. Nyden and G.A. Petersson, Complete basis set correlation energies. I. The asymptotic convergence of pair natural orbital expansions. J. Chem. Phys. 75 (1981) 1843-62.

31. G.A. Petersson, A. Bennett, T.G. Tensfeldt, M.A. Al-Laham, W.A. Shirley, and J. Mantzaris, A complete basis set model chemistry. I. The total energies of closed-shell atoms and hydrides of the first-row atoms. J. Chem. Phys. 89 (1988) 2193-218

32. Gaussian 16, Revision C.01, M. J. Frisch, G. W. Trucks, H. B. Schlegel, G. E. Scuseria, M. A. Robb, J. R. Cheeseman, G. Scalmani, V. Barone, G. A. Petersson, H. Nakatsuji, X. Li, M. Caricato, A. V. Marenich, J. Bloino, B. G. Janesko, R. Gomperts, B. Mennucci, H. P. Hratchian, J. V. Ortiz, A. F. Izmaylov, J. L. Sonnenberg, D. Williams-Young, F. Ding, F. Lipparini, F. Egidi, J. Goings, B. Peng, A. Petrone, T. Henderson, D. Ranasinghe, V. G. Zakrzewski, J. Gao, N. Rega, G. Zheng, W. Liang, M. Hada, M. Ehara, K. Toyota, R. Fukuda, J. Hasegawa, M. Ishida, T. Nakajima, Y. Honda, O. Kitao, H. Nakai, T. Vreven, K. Throssell, J. A. Montgomery, Jr., J. E. Peralta, F. Ogliaro, M. J. Bearpark, J. J. Heyd, E. N. Brothers, K. N. Kudin, V. N. Staroverov, T. A. Keith, R. Kobayashi, J. Normand, K. Raghavachari, A. P. Rendell, J. C. Burant, S. S. Iyengar, J. Tomasi, M. Cossi, J. M. Millam, M. Klene, C. Adamo, R. Cammi, J. W. Ochterski, R. L. Martin, K. Morokuma, O. Farkas, J. B. Foresman, and D. J. Fox, Gaussian, Inc., Wallingford CT, 2016.

33. H.Y. Afeefy, J.F. Liebman, and S.E. Stein, Neutral Thermochemical Data in NIST Chemistry WebBook, NIST Standard Reference Database Number 69, Eds. P.J. Linstrom and W.G. Mallard, National Institute of Standards and Technology, Gaithersburg MD, 20899, Available at: http://webbook.nist.gov, (retrieved October 31, 2016)

34. G.A. Poskrebyshev, Re-evaluation of the standard thermochemical properties of the $\mathrm{Al}_{2}$ cluster on the basis of CBS thermochemistry of isogyric reactions and correlation dependencies. Computational and Theoretical Chemistry. 1130 (2018) 24-32

35. G.A. Poskrebyshev, The values of $\Delta_{\mathrm{f}} \mathrm{G}_{\mathrm{T}}^{\mathrm{o}}\left(\mathrm{Al}_{\mathrm{n}}\right)(\mathrm{n}=3-10$ ATOMS, $\mathrm{T}$ [?] $3000 \mathrm{~K})$, determined using the ROCBS-QB3 values of $\mathrm{S}^{\circ} \mathrm{T}\left(\mathrm{Al}_{\mathrm{n}}\right)$ and of the corrected values of $\Delta_{\mathrm{f}} \mathrm{H}^{\circ}{ }_{\mathrm{T}}\left(\mathrm{Al}_{\mathrm{n}}\right)$. Computational and Theoretical Chemistry. 1143 (2018) 52-63

36. G.A. Poskrebyshev, Values of $\left(\Delta_{\mathrm{f}} \mathrm{H}^{\mathrm{o}}{ }_{298.15}\right)_{(\mathrm{g})}$ and $\left(\mathrm{S}^{\mathrm{o}}{ }_{298.15}\right)_{(\mathrm{g})}$ of the several N,Nethylenebisalkaneamides calculated using RB3LYP/6-31G(D,P) and CBS-4M approaches, and 
their correlation dependencies. Computational and Theoretical Chemistry. 1105 (2017) 77-88

37. E. Goos, A. Burcat and B. Ruscic, Extended Third Millennium Ideal Gas and Condensed Phase Thermochemical Database for Combustion with Updates from Active Thermochemical Tables. Update of Third Millennium Ideal Gas and Condensed Phase Thermochemical Database for Combustion with Updates from Active Thermochemical Tables Alexander Burcat and Branko Ruscic Report ANL 05/20 and TAE 960 Technion-IIT, Aerospace Engineering, and Argonne National Laboratory, Chemistry Division, September 2005

38. V.B. Oyeyemi, J.A. Keith, and E.A. Carter, Accurate Bond Energies of Biodiesel Methyl Esters from Multireference Averaged Coupled-Pair Functional Calculations. J. Phys. Chem. A. 118 (2014) 73927403

39. V.B. Oyeyemi, D.B. Krisiloff, J.A. Keith, F. Libisch, M. Pavone, and E.A. Carter, Size-extensivitycorrected multireference configuration interaction schemes to accurately predict bond dissociation energies of oxygenated hydrocarbons. J. Chem. Phys. 140 (2014) 044317

40. X. Li, X. Xu, X. You, and D.G. Truhlar, Benchmark Calculations for Bond Dissociation Enthalpies of Unsaturated Methyl Esters and the Bond Dissociation Enthalpies of Methyl Linolenate. J. Phys. Chem. A 120 (2016) 4025-4036

41. ChemRate v. 1.5.10. V. Mokrushin, V. Bedanov, W. Tsang, M.R. Zachariah, V.D. Knyazev, W.S. McGivern, NIST, USA, 1996-2011

42. Precomputed scaling factors. NIST Computational Chemistry Comparison and Benchmark Database - SRD 101. III.B.3.a. (available at https://cccbdb.nist.gov/vibscalejust.asp)

43. G.A. Poskrebyshev, The values of $\Delta_{\mathrm{f}} \mathrm{H}^{\circ}{ }_{298.15}\left(\mathrm{Al}_{\mathrm{n}} \mathrm{O}_{\mathrm{m}} \mathrm{H}_{\mathrm{p}}\right)$, calculated using the CBS correction dependencies, as well as the thermochemistry of the isodesmic/homodesmotic reactions. Computational and Theoretical Chemistry. 1164 (2019) 112540

44. G.A. Poskrebyshev, M.R. Kudasheva, A.A. Poskrebyhev, Thermochemistry of the reactions $\mathrm{HO}_{2}$ (or $\left.\mathrm{CH}_{3} \mathrm{O}_{2}\right)+\mathrm{C}_{6} \mathrm{H}_{5} \mathrm{CH}_{2} \mathrm{C}_{6} \mathrm{H}_{4} \mathrm{OH}=\mathrm{H}_{2} \mathrm{O}_{2}\left(\right.$ or $\left.\mathrm{CH}_{3} \mathrm{O}_{2} \mathrm{H}\right)+\mathrm{C}_{13} \mathrm{H}_{11} \mathrm{O}$. GORENIE I VZRYV (MOSKVA) - COMBUSTION AND EXPLOSION. 13(4) (2020) 9-19

45. C.E. Check and T.M. Gilbert, Progressive Systematic Underestimation of Reaction Energies by the B3LYP Model as the Number of C-C Bonds Increases: Why Organic Chemists Should Use Multiple DFT Models for Calculations Involving Polycarbon Hydrocarbons. J. Org. Chem. 70 (2005) 9828-9834

46. H. Kruse, L. Goerigk, and S. Grimme, Why the Standard B3LYP/6-31G* Model Chemistry Should Not Be Used in DFT Calculations of Molecular Thermochemistry: Understanding and Correcting the Problem. J. Org. Chem. 77 (2012) 10824-10834

47. P.R. Schreiner, A.A. Fokin, R.A. Pascal, Jr., and A. de M. Many Density Functional Theory Approaches Fail To Give Reliable Large Hydrocarbon Isomer Energy Differences. Org. Lett. 8(17) (2006) 36353638

48. M.D. Wodrich, C. Corminboeuf, and P.R. Schleyer, Systematic Errors in Computed AlkaneEnergies Using B3LYP and Other Popular DFT Functionals. Org. Lett. 8(17) (2006) 3631-3634

49. M.W. Chase, Jr., C.A. Davies, J.R. Downey, Jr., D.J. Frurip, R.A. McDonald, and A.N. Syverud. NIST-JANAF Thermochemical Tables. Fourth Edition. J. Phys. Chem. Ref. Data. Monograph 9. (1998) 1-1951 